\title{
Components of inhibition in autogenous- and reactive-type obsessive-compulsive disorder: dissociation of interference control
}

Jie Fan ${ }^{\mathrm{a}}$, Wanting Liu ${ }^{\mathrm{a}}$, Hui Lei ${ }^{\mathrm{a}, \mathrm{b}}$, Lin Cai ${ }^{\mathrm{c}}$, Mingtian Zhong ${ }^{\mathrm{d}}$, Jiaojiao Dong ${ }^{\mathrm{a}}$, Cheng Zhou ${ }^{\mathrm{a}}$, Xiongzhao Zhua*

${ }^{a}$ Medical Psychological Institute, Second Xiangya Hospital, Central South University, Changsha 410011, PR China

${ }^{\mathrm{b}}$ College of Education, Hunan Agriculture University, Hunan, Changsha 410128, PR China

${ }^{\mathrm{c}}$ School of Sociology and Psychology, Southwest University for Nationalities, Chengdu, Sichuan 610041, PR China

${ }^{\mathrm{d}}$ Center for Studies of Psychological Application, South China Normal University, Guangzhou 510631, PR China

* Corresponding author at: Medical Psychological Institute of the Second Xiangya Hospital, Central South University, Changsha, Hunan, PR China. Tel.: +86 731 85292126; fax: +86 731 85361328. E-mail addresses: xiongzhaozhu@163.com. 


\section{Abstract}

Obsessive-compulsive disorder (OCD) is characterized by unwanted, intrusive thoughts (obsessions) and/or repetitive, ritualistic behaviors (compulsions). Findings related to the two components of inhibition, namely interference control and behavioral inhibition, among OCD patients have been inconsistent. It might be that this inconsistency is due to the heterogeneity among OCD cases representing multiple subtypes of OCD, such as autogenous obsessions and reactive obsessions types (AOs vs. ROs). AOs and ROs are distinguished by the category of their most disturbing obsessions. The purpose of this study was to systematically examine whether inhibition functions differ between $\mathrm{AO}$ and $\mathrm{RO}$ patients. We assessed interference control and behavioral inhibition with the emotional Stroop task (EST) and stop-signal task (SST), respectively, in $42 \mathrm{AOs}, 55 \mathrm{ROs}$ and 62 healthy controls (HCs) and event-related potentials (ERPs) were recorded in a random subset of these subjects (25 AOs, 25 ROs, and $31 \mathrm{HCs})$. Results showed that in the EST, AOs exhibited longer reaction times (RTs) for color-naming positive-, negative-, and neutral-valence word stimulus than both ROs and HCs, and demonstrated larger P2 and less negative N450 amplitudes than HCs and larger P3 amplitudes than ROs and HCs. In the SST, both AOs and ROs showed lengthened stop signal reaction time (SSRT) and reduced Stop-P3 amplitudes in successful inhibition (SI) trials compared to the HC group. These present findings suggest that behavioral inhibition impairment may reflect a common pathology in both the autogenous- and reactive-type OCD patients, whereas interference inhibition impairment appears to be specific to patients with autogenous obsessions. These findings strengthened the insight into the clinical heterogeneity and pathophysiology of OCD. 
Key words emotional Stroop task; autogenous-reactive obsessions; behavioral inhibition; stop-signal task; event-related potentials (ERPs) 


\section{Introduction}

Obsessive-compulsive disorder (OCD) is a relatively common and potentially debilitating neuropsychiatric disorder characterized by recurrent intrusive thoughts, urges or images (obsessions), and/or repetitive behaviors or mental acts (compulsions) (APA, 2013). Although the neurobiological mechanism underlying OCD is not yet fully understood, numerous neuropsychological studies have pointed to likely inhibitory deficits in OCD patients (Bannon et al., 2002; Penadés et al., 2005; Lei et al., 2013). Consequently, it has been suggested that an inhibition deficit may be a major contributor to OCD pathophysiology and potentially characterizes an OCD endophenotype (Chamberlain et al., 2005).

Inhibition encompasses two domains, namely interference control and behavioral (motor) inhibition (van Velzen, 2014). Interference control refers to the ability to inhibit one's attention from being drawn to irrelevant information (Nigg, 2000). Classical assessments of interference control include Flanker tasks and (classical or emotional) Stroop tasks. Behavioral inhibition involves the regulation of prepotent and automatic responses. Historically, behavioral inhibition has been assessed primarily with Go/No-go tasks and stop-signal tasks (SSTs). OCD patients tend to perform poorly in Stroop tasks, Go/No-go tasks, and SSTs, pointing to characteristic impairments in both domains of inhibition (Kwon et al., 2003; Penadés et al., 2005; Rao et al., 2010; Kang et al., 2013). However, there have been inconsistencies among some of the findings (Moritz et al., 2008; Maltby et al., 2005). Specifically, Kowalczyk (2006) reviewed a number of neuropsychological studies examining cognitive inhibition function in patients with OCD (mainly negative priming, thought suppression, and directed forgetting domains) and concluded that the results may be not support the hypothesis of general cognitive inhibitory deficits in OCD patients. 
It could be that inconsistencies in OCD research findings are due to the heterogeneous nature of OCD, wherein different OCD types may be characterized by differences in inhibition function. One of the most popular ways to deal with the heterogeneity of OCD is to derive symptom dimensions using the factor analytic approach based on responses to Yale-Brown Obsessive Compulsive Scale-Symptom Checklist (Y-BOCS-SC). For example, Mataix-Cols et al. (1999) used a category-based factor analysis in 354 OCD patients and identified five OC symptom dimensions which contained symmetry/ordering, hoarding, contamination/cleaning, aggression/checking and sexual/religious; Katerberg et al. (2010) recently item-level factor analyzed 1,224 OCD patients and derived a five-factor model which included taboo, contamination/cleaning, doubts, superstitions/rituals and symmetry/hoarding. As above, due to the use of different methodologies and varying sample sizes, some inconsistencies in the results of factor analysis were existed, though generally more similarities than differences. Previous literatures have revealed that different clinical symptom dimensions presented in OCD patients may be account for their differences in comorbidity patterns (Hasler et al., 2005), treatment responses (Mataix-Cols et al., 1999), genetic underpinnings (Katerberg et al., 2010; Iervolino et al., 2011) and neuroimaging findings (Mataix-Cols et al., 2004). However, regarding to neuropsychological studies, the results were mostly negative (Mataix-Cols et al., 2005).

Recently, a somewhat different two-group classification model for OCD patients was proposed by Lee and Kown (2003). These authors proposed that obsessions can be categorized as autogenous or reactive. Autogenous obsessions usually have no clear external triggers, or only a symbolic trigger and they are always perceived as ego-dystonic and aversive. Typical autogenous obsessions include thoughts, images, or impulses that are often about aversive, immoral, 
aggressive, or sexual contents. Meanwhile, reactive obsessions are triggered by identifiable external stimuli in somewhat realistic, logical, or rational ways. Reactive obsessions include thoughts, concerns, or doubts commonly related to contamination, mistakes, accidents, asymmetry, or loss. Evidence for this two-type classification of obsessions was obtained by a factor-analysis of responses to the Revised Obsessive Intrusion Inventory (ROII), which was developed by Purdon and Clark $(1993,1994)$ and designed to focus on the obsessive, intrusive thoughts, images and impulses (obsessions). Lee and Kwon (2003) confirmed the two-factor structure of ROII corresponding to autogenous and reactive obsession, and this structure was also replicated by Belloch et al. (2004), Moulding et al. (2007) and He et al. (2014) in different samples. According to this model, each OCD patient can be further classified into autogenous or reactive obsessions subtypes (AO vs. RO subtype) on the basis of the category of their reported primary and most disturbing obsession (Lee \& Kown, 2003; Lee et al., 2005a). The autogenous-reactive OCD subtypes classification has been validated and supported by several type of discriminating studies (Lee \& Kown, 2003; Lee et al., 2005a; Lee et al., 2005b; Belloch et al., 2010; Lee \& Telch, 2010; Besiroglu et al., 2011; Subirà et al., 2013). Compared to other existing symptom dimensions models, the autogenous-reactive subtype model was only based on obsessional presentations without regard to the overt behavioral symptoms, which were proposed to be grouped with obsessions together, and it only conceptualized core symptoms of OCD across different domains and thus reduced the problem of multiple (traditional) subtypes in the same individual with OCD (McKay et al., 2008). The autogenous-reactive subtype model was also proved to have good temporal stability (Besiroglu et al., 2007).

Moreover, it's interesting that some studies have revealed that AO and RO subtypes of OCD 
patients may differ in inhibition performances. For example, utilizing a Go/No-go task with a reversal component, which referred to that previously learned go and no-go stimulus were presented in reversed roles, and was sensitive to assessment of inhibition of previous distracter information), Lee et al. (2009) found longer response delays between the standard and reversed stimulus sets in autogenous-type patients as compared to reactive-type and healthy control groups (HCs), which indicated poor inhibition processing of irrelevant distracters in AOs. Additionally, using a latent inhibition task, Lee and Telch (2010) found that an autogenous group failed to display latent inhibition (LI) effect, whereas reactive and control groups did. LI effect was defined as the delay of learning to a stimulus that was previously presented as a distracter as compared with learning to a novel stimulus (Lubow \& Gewirtz, 1995). Therefore LI was also primary an index of attentional inhibitory processing deficits. Hence, both of these studies suggest that inhibition deficits may be a selective characteristic of autogenous OCD patients and heterogeneity among OCD cases, such as $\mathrm{AO}$ and RO types can probably help us to identify the inconsistence among inhibition in OCD patients. However, this distinction was not replicated by Aydin et al. (2014), who found similarly impaired inference inhibition performance in AOs and ROs when performing a Stroop task.

The inconsistent findings may be due, at least in part, to sample limitations. The prior studies were conducted with undergraduate student populations, not clinical samples (Lee et al., 2009; Lee \& Telch, 2010), and the study by Aydin et al. (2014) had a small sample size (30 reactive patients, 14 autogenous patients). Besides, the abovementioned studies have other limitations. First, the study designs may not have been well-suited to elucidating behavioral inhibition in OCD. The Go/No-go task used in Lee et al's (2009) study had been modified such that the Go stimulus 
probability was $50 \%$ (rather than the standard $75 \%$ ). The resultant $1: 1$ ratio may have rendered the task too easy, and thus be insensitive to potential group differences. Second, since the aforementioned studies were reaction time (RT) studies, the cerebral mechanisms underlying the putative interference control and behavioral inhibition dysfunctions of autogenous and reactive OCD patients have not been explored. In this regard, event-related potential (ERP) electrophysiology is a useful tool for probing real-time aspects of cognitive processes because it reflects discrete changes in brain activity (Friedman, 2000). In light of these limitations, further studies which conduct in larger clinical samples and use more classical paradigms and more sensitive measures, are needed to clarify whether and how AO and RO OCD patients differ in both the interference and behavioral inhibition functions.

Emotional Stroop task (EST) is a widely used instrument for assessment of interference inhibition. In this task, participants are presented with emotional words (negative, positive and neutral words) in different colored fonts. They are instructed to ignore word meanings and respond to the text color as soon as possible. As the processing of word meaning is somewhat automatic and habitual, the EST then actually accesses the extent to which persons can inhibit the automatic processing of emotional word meanings. Compared with the classical Stroop task, the EST can further illustrate the attentional biases of emotional salience as emotional words were used in this paradigm. Attentional biases are usually indicated by negative and positive interference scores which are calculated by subtracting mean RTs for the neutral word set from that of negative and positive word sets respectively. Meanwhile, we are curiously to explore whether and how different negative biases patterns would further affect the results. As mentioned, autogenous obsessions are usually about the sexual, aggressive, or immoral contents and thus characterized by a more 
repugnant and negative nature than reactive obsessions. Hence, we may also preliminarily hypothesize an additional negative bias in AOs. ERP studies of subjects performing EST often reported data related to a P1-N1-P2-P3-N450 complex of ERP components (Pérez-Edgar \& Fox, 2003; Thomas et al., 2007; van Hooff et al., 2008). In general, sensory-evoked P1 (80-130ms) and N1 (140-200ms) components over the lateral occipital scalp are both indexes of spatial attention (Hillyard \& Anllo-Vento, 1998). While, to go further, these two components may reflect two qualitatively distinct mechanisms of attention, one that operates by enhancing the processing of information within the focus of attention and another that operates by suppressing information falling outside the attended zone (Luck \& Hillyard, 1993). P2 is maximal at frontal sites with a latency of $150-250 \mathrm{~ms}$. In the current literature, this positivity has been thought to associate with target detection, stimulus encoding, interference solution and the salience and relevance evaluation (Potts, 2004; Freunberger et al., 2007; Finke et al., 2011). Notably, researchers suggested that P2 was related to stimulus (target)-classification and further linked this ERPs component to inhibition of irrelevant and distracting information especially in the condition where the target and the irrelevant stimuli appeared simultaneously (Freunberger et al., 2007; Finke et al., 2011). P3b, clearly identifiable at parietal electrodes within $300-450 \mathrm{~ms}$, is thought to reflect the semantic conflict processing during the stimulus evaluation stage in EST (Zurrón et al., 2009, 2013). There were previous studies revealing that P1, N1, P2 and P3b could be affected by emotional valence of visual stimulus, however, inconsistent results were reported (Carretié et al., 2004; Herbert et al., 2006; Thomas et al., 2007; Thomas et al., 2013; Zurrón et al., 2013; Fan et al., 2014). Another important ERPs component in Stroop task is N450, a frontal-central negativity peaking around 400-500ms, which can usually differentiate incongruent trials from congruent and neutral trials 
and is thought to reflect conflict detection and/or resolution (West \& Alain, 2000; Qiu et al., 2006). It's worthy to note that some authors proposed that P3b and the superimposed N450 in the time range of 300-450 might be both associated with the semantic conflict related processes in Stroop task (West \& Alain, 2000; West et al., 2005). Generally, P1, N1 and P2 represent more early, sensory, and automatic cognitive stages, while P3b and N450 reflect the more controlled, high-level and later processing stages.

The SST is a classic paradigm for assessment of behavioral inhibition. All SST trials begin with the presentation of a "go" stimulus that requires a fast and accurate behavioral response. In some trials (stop trials), a stop signal follows the go stimulus and subjects are instructed to inhibit their response when the stop signal is presented. The stop-signal reaction time (SSRT) parameter extracted from this task appears to be a direct and effective measurement of behavioral inhibition, with a prolonged SSRT indicating poor inhibition ability (Logan \& Cowan, 1984). SSRT calculation depends on three indices: mean reaction time for correct Go trials (mean Go RT), percent successful inhibition stop trials $[\mathrm{P}(\mathrm{i})]$, and SOA (stimulus onset asynchrony, also stop-signal delay, SSD in SST). For SST, there are usually two ways to set the SOA. One is several specified SSDs (e.g. $250 \mathrm{~ms}, 350 \mathrm{~ms}$, or $450 \mathrm{~ms}$ ) and the other is the tracking algorithm (Logan et al., 1997), where the SSD is dynamically varied depending on the participant's performance on previous stop trials (following successful stop trials, the SSD becomes longer, making the subsequent stop trial more difficult or vice-versa). Tracking algorithm method is more suitable for studies assessing behavioral inhibition between patients and controls because it yields smaller between-subject performance variability than fixed delay method (Fauth-Bühler et al., 2012). Regarding to SST, two ERP components related to inhibition were N2 and P3 in stop trials 
(Stop-N2, Stop-P3). N2 is typically maximal at frontal-central sites and occurs in a latency of 200-300ms. Both go and stop trials can elicit N2 component. It was proposed that N2 might well occur at a pre-motor level and related to a general process of response selection (Falkenstein et al., 1999; Gajewski et al., 2008). However, as in stop trials, it additionally involves the inhibition of a premature response plan, or alternatively, the detection or resolution of response conflict between Go and Stop response tendencies, the Stop-N2 is intensified or prolonged (Gajewski \& Falkenstein, 2013). Stop-P3 is a positive-going wave emerging 300-500ms after the stop-signal, and it usually has maximal amplitude in central or fronto-central region (Falkenstein et al., 2002). Stop-P3 is thought to reflect a late stage of the acute inhibition process and further thought to be associated with efficiency of inhibitory or evaluation of the inhibition process (Gajewski \& Falkenstein, 2013).

To sum up, the current study was aimed to use EST and SST to conduct a systematic comparison of behavioral performance and electrophysiological mechanisms of interference control and behavioral inhibition between autogenous and reactive OCD patients in a relatively large, medication-free clinical sample. Our study was designed to test the hypothesis that heterogeneity, specifically the autogenous-reactive OCD types, can explain inconsistent results in studies of interference control and behavioral inhibition in OCD patients. Preliminarily, we predict more pronounced inhibition dysfunctions and negative bias in AOs. Behaviorally lengthened color-naming RT, along with alterations in amplitudes or latencies of ERPs components regardless of word type effect in EST would implicate the interference inhibition dysfunction. Meanwhile, the behavioral inhibition deficit would be indicated by longer SSRT and anomalies in Stop-N2 and/or Stop-P3 in SST. Further, larger negative RT interference and word valence effects on either 
early, sensory (P1/N1/P2) and/or later, more controlled (P3b/N450) ERPs components could provide evidence for negative bias. However, given that this is the first study to explore ERPs mechanism of inhibition-deficit differences between autogenous and reactive OCD patients, we might choose not to formulate a prior hypothesis regarding to the related specific ERPs component abnormalities.

\section{Methods}

\subsection{Subjects}

Ninety-seven patients who were diagnosed with OCD by two psychiatrists using the Structure Clinical Interview of DSM-IV (SCID) were recruited from the psychology clinic at the Second Xiangya Hospital of Central South University and included in the study. Subjects who met criteria for depression or any other comorbid psychiatric disorders (Axis I or Axis II), and who had a history of major medical or neurological problems and alcohol or substance dependence were excluded. All participants were seeking treatment for the first time and thus were medication-free.

Sixty-two age- and gender-matched healthy people were recruited to serve as the HC group. They were students or staff at Central South University. None of them had a history of any psychiatric illnesses, major medical or neurological problems, or any alcohol and substance dependence.

All participants were between 16 and 35 years of age and had at least 6 years of formal education. No subject had color blindness and all had normal or corrected to normal vision. The participants signed a consent form before participating in this research, and the study was approved by the Ethics Committee of the Second Xiangya Hospital of Central South University. 


\subsection{Procedure}

After being diagnosed, participants with OCD underwent a semi-structured interview in which sociodemographic data (e.g. age, gender, occupation, education level) and information about clinical variables (e.g. age onset, medical condition, history of disease) were recorded. The evaluator also completed the Yale-Brown Obsessive-Compulsive Scale (Y-BOCS) including the checklist (Goodman et al., 1989) to assess OCD severity and obtain a symptom profile for each participant. Furthermore, patients were asked to report their primary, most upsetting obsession, and the evoking stimulus, ego-dystonicity, and perceived irrationality of that obsession were recorded.

Two psychiatrists with extensive experience in OCD diagnosis reviewed the records of each patient independently and assigned each patient to the AO or RO group based on the category of the patient's reported most upsetting obsessions. Previous studies have demonstrated the utility of classifying patients as autogenous or reactive types based on their reported primary obsessions (Belloch et al., 2010; Besiroglu et al., 2011; Subira et al., 2013; Aydin et al., 2014). In accordance with the model of Lee \& Kwon (2003), obsessions were classified as autogenous type if they dealt with sexual, aggressive, violent, or immoral (including perceived blasphemy) content, and were classified as reactive type if they were related to contamination fear, mistakes, disorder, or asymmetry issues. The inter-rater reliability for group classification was excellent (Spearman's correlation coefficient $=0.98$ ), and disagreement was resolved through discussion. Of the 97 OCD patients enrolled, 42 were classified into the $\mathrm{AO}$ group and 55 into the $\mathrm{RO}$ group.

All participants completed the Beck Depression inventory (BDI; Beck et al., 1961) and State 
Trait Anxiety Inventory (STAI; Spielberger et al., 1983). ERP experiments were conducted in randomly selected subsets of each group, including $25 \mathrm{AOs,} 25 \mathrm{ROs}$, and $31 \mathrm{HCs}$ during performance of the behavioral tasks.

\subsection{Behavioral task administration}

Both the EST and SST were administered by a trained neuropsychologist. Participants were seated $60 \mathrm{~cm}$ from the computer screen in a quiet environment. E-prime software was used for stimulus presentation and response recording.

\subsubsection{EST}

A total of 45 emotional words (15 negative, 15 positive, and 15 neutral; see Appendix A) were selected from the Chinese Affective Word System which was developed by Psychology Department of the Chinese Academy of Science (Wang et al., 2008b). They asked 64 undergraduate students using 9-point likert scale to rate the valence levels and arousal values for their list of words, and then established the database (Wang et al., 2008b). On the basis of their work, we selected our word stimulus and wrote our experimental program. We did not include words that were obviously symptom-related to avoid individual- and symptom-specific effects. Repeated-measures analysis of variance (ANOVA) was adopted to compare valence levels [range, 1 (very unpleasant) to 9 (very pleasant)] and arousal [1 (calm) to 9 (excited)] across the three emotional word sets. Results showed that there were significant word type effects both for valence level $\left(\mathrm{F}_{2,28}=4069.60, p<.001\right)$ and arousal value $\left(\mathrm{F}_{2,28}=16.51, p<.001\right)$. Specifically, the positive word set had a higher mean $( \pm$ SEM) valence value $(7.22 \pm 0.18)$ than that obtained for the neutral $(5.11 \pm 0.06)$ and negative $(2.51 \pm 0.22)$ word sets $(p<.001)$, and the neutral word set had 
a higher mean valence value than the negative word set $(p<.001)$. The positive $(5.71 \pm 0.72)$ and negative $(6.16 \pm 0.65)$ word sets had higher mean arousal values than the neutral word set $(4.53 \pm$ $0.82 ; p<.001)$, and arousal values did not differ between the positive and negative word sets $(p$ $=.096)$.

Words were presented in three word-set blocks of 60 trials each. Within each block, 15 different words from one category were repeated four times with each time projected in one of the four colors (red, green, yellow, blue) respectively. The block design was adopted because it is more effective in eliciting emotion-word Stroop interference than an intermixed design (Holle et al., 1997). The participants were instructed to respond to the word color as quickly as possible by pressing the appropriate button ("D" for red, "F" for green, "J" for yellow, "K" for blue), while ignoring the word meaning. They performed 36 practice trials before data were collected. All stimuli were presented in the center of a computer screen against a black background with a visual angle of $3.45^{\circ} \times 4.8^{\circ}$. Before the stimuli appeared, a fixation cross appeared on the screen for 500 ms. The stimulus duration was $200 \mathrm{~ms}$ and the inter-stimuli interval varied randomly between 800 ms and $1400 \mathrm{~ms}$. The presentation orders of the three blocks, the words and words colors within each block were randomized for each participant. 


\section{Appendix A}

Words used in the current study.

\begin{tabular}{cccccc}
\hline \multicolumn{2}{c}{ Negative } & \multicolumn{2}{c}{ Positive } & \multicolumn{2}{c}{ Neutral } \\
\hline 罪恶 & sin & 父母 & parents & 医生 & doctor \\
灾害 & disaster & 智慧 & wisdom & 事物 & thing \\
悲剧 & tragedy & 奖金 & bonus & 皇帝 & emperor \\
遗体 & remains & 美女 & beauty & 阁下 & milord \\
苍蝇 & flies & 爱情 & love & 对策 & measures \\
地狱 & hell & 鲜花 & flowers & 纪律 & discipline \\
疾病 & diseases & 笑容 & smile & 命运 & fate \\
小偷 & thief & 冠军 & champion & 开支 & expenditure \\
耻辱 & shame & 亲人 & relatives & 狮子 & lion \\
凶手 & murderer & 财富 & wealth & 铁路 & railway \\
敌人 & enemy & 家庭 & family & 消防 & firefighting \\
恶魔 & devil & 信心 & confidence & 心脏 & heart \\
疯子 & maniac & 才华 & talent & 宫廷 & court \\
棺材 & coffin & 英雄 & hero & 烈士 & martyr \\
死刑 & death & 盈利 & earnings & 法制 & legal \\
\hline
\end{tabular}

\subsubsection{SST}

In the SST, "go" trials (70\%) and "stop" trials (30\%) were randomly intermixed. In go trials, a single go stimulus ("X" in black, visual angle approximately $2^{\circ} \times 2^{\circ}$ ) was presented. In stop trials, the initial black " $\mathrm{X}$ " changed to red. Participants were asked to press the space button quickly when the black " $X$ " appeared on the screen and to inhibit their response when the " $X$ " turned into red. Each participant performed 20 practice trials, and then began the formal SST task consisting of four 100-trial blocks. Before the black "X" appeared in each trial, a fixation cross appeared on the screen for $500 \mathrm{~ms}$. A tracking algorithm was adopted for the stop trials such that the stop-signal delay (SSD) was adjusted in 50-ms increments, increasing after successful stops and decreasing after stop failures to titrate a $50 \%$ inhibition rate. The initial SSD was set to $250 \mathrm{~ms}$, with an upper limit of $1000 \mathrm{~ms}$ and a lower limit of $0 \mathrm{~ms}$. 


\subsection{ERP data acquisition}

Electroencephalogram (EEG) data (digitized at $1000 \mathrm{~Hz}$ with a band pass of $0.05-200 \mathrm{~Hz}$ ) were recorded from $30 \mathrm{Ag} / \mathrm{AgCl}$ electrodes via a 32-channel cap (Easy-cap) based on a 10-20 system. A reference electrode was placed on the left mastoid. Horizontal and vertical electrooculograms were performed on the left and right external canthus and above and below the left eye, respectively. Electrode impedances were kept below $5 \mathrm{k} \Omega$.

\subsection{Data analysis}

\subsubsection{Demographic and clinical data analysis}

One-way ANOVAs, $t$-tests, or the Chi-square tests were used to compare the demographic and clinical variables among three groups.

\subsubsection{Behavioral data analysis}

Mean RTs for the negative, positive, and neutral word conditions in the EST were calculated for each participant. Trials in which no reaction occurred, the respondent answered incorrectly, or the RT was more than two standard deviations from the participant's condition mean were excluded from the analysis. RT and accuracy data were analyzed with a 3 (group: AOs, ROs, Control) $\times 3$ (within-subjects factor, word type: negative, positive, neutral) repeated-measures analysis of variance. Interference scores were calculated by subtracting the mean RT for the neutral word set from that of negative and positive word sets respectively, and both subjected to a one-way ANOVA to reveal whether there was a group difference.

For SST, the following variables were extracted for each participant: mean reaction time for correct go trial (GoRT), standard deviation of the SDs of the Go RTs (GoRTs SD), percent correct 
go trials, percent successful inhibition stop trials [P(i)], stop-signal delay (SSD), and SSRT. SSRT was computed by subtracting the average SSD from mean correct GoRT (Odlaug et al., 2010; Galimberti et al., 2012). Participants whose $P(\mathrm{i})$ was outside the $25-75 \%$ range were excluded from the final analysis (in order not to violating assumptions underlying the horse-race model of SST, and to yield reliable SSRT; in addition, this can guarantee a minimum of 30 trials especially for ERPs average (Band et al., 2003; Congdon et al., 2012)). One-way ANOVAs were conducted to compare these variables among the three groups.

Additionally, correlation analyses (Pearson $r$ ) were used to examine associations between indexes of interference inhibition and response inhibition, with demographic variables (BDI, Y-BOCS, or STAI scores) in AOs and ROs separately.

\subsubsection{ERP data analysis}

Scan 4.3 software (NeuroScan Inc., USA) was used to analyze the EEG data offline. The recordings were firstly re-referenced to an average of the left and right mastoid electrodes, and then a regression procedure was used to correct for eye movements (Gratton et al., 1983).

For the EST, EEG epochs were defined as $100 \mathrm{~ms}$ pre- to $800 \mathrm{~ms}$ post-stimulus, and the pre-stimulus baseline was corrected. After subsequent automatic artifact rejection of $\pm 100 \mu \mathrm{V}$ with a 30-Hz low-pass filter ( $24 \mathrm{~dB} /$ octave), the EEG activities for negative, positive, and neutral conditions for each participant ( $\geq 30$ trials) were averaged. On the basis of earlier studies and visual inspection of the grand mean waveforms, peak amplitudes for P1, N1, P2, N450, and mean amplitude for P3b were calculated in the following time windows: P1 (50-90 ms), N1 (90-130 ms), P2 (180-250 ms), P3b (280-400 ms), and N450 (300-450ms). According to the scalp distributions of each ERPs component, we focused on the occipital electrodes (O1, Oz, O2) for P1 
and N1, the frontal and central electrodes (F3, Fz, F4, C3, Cz, C4) for P2 and N450, and the parietal electrodes (P3, Pz, P4) for P3b. Latency of each ERPs component were acquired where largest amplitudes were quantified: $\mathrm{Oz}$ for $\mathrm{P} 1$ and $\mathrm{N} 1, \mathrm{Fz}$ for $\mathrm{P} 2, \mathrm{Pz}$ for $\mathrm{P} 3$, and $\mathrm{Cz}$ for $\mathrm{N} 450$. Whereafter, $\mathrm{P} 1$ and $\mathrm{N} 1$ data were analyzed with a 3 (group: AOs, ROs, HCs) $\times 3$ (word type: negative, positive, neutral) $\times 3$ (electrodes: O1, Oz, O2) mixed repeated-measures ANOVA. P2 and N450 data were submitted to a 3 (group: AOs, ROs, HCs) $\times 3$ (word type: negative, positive, neutral) $\times 2$ (region: frontal, central) $\times 3$ (hemisphere: left, midline, right) mixed repeated measures ANOVA. P3b data were analyzed with a 3 (group: AOs, ROs, HCs) $\times 3$ (word type: negative, positive, neutral) $\times 3$ (electrodes: $\mathrm{P} 3, \mathrm{Pz}, \mathrm{P} 4)$ mixed repeated-measures ANOVA. Word type, region, hemisphere and electrodes were as within-subjects factors. In addition, all latency data were submitted to 3 (group: $\mathrm{AOs}, \mathrm{ROs}, \mathrm{HCs}$ ) $\times 3$ (word type: negative, positive, neutral) mixed repeated measures ANOVA.

For the SST, both the stop-signal trials and correct-go trials were analyzed. For stop-signal trials, EEG data were segmented into 100 -ms pre- and 800-ms post-stop-signal onset epochs, and pre-stop-signal baseline was corrected. EEG activities for successful inhibition (SI) and failed inhibition (FI) conditions for each participant ( $\geq 30$ trials) were averaged after automatic artifact rejection $( \pm 100 \mu \mathrm{V})$ with a $30-\mathrm{Hz}$ low-pass filter (24 dB/octave). While, for correct-go trials, EEG data were segmented into 100 -ms pre- and 800 -ms post-go-signal onset epochs, and pre-go-signal baseline was corrected. EEG activities for correct-go trials were then averaged for each participant after automatic artifact rejection $( \pm 100 \mu \mathrm{V})$ with a $30-\mathrm{Hz}$ low-pass filter (24 dB/octave). Based on earlier studies and visual inspection of grand mean waveforms, peak amplitudes for Stop-N2 and mean amplitudes for Stop-P3 in both SI and FI conditions were calculated in the following time 
windows: $175-225 \mathrm{~ms}$ (Stop-N2) and 280-350 ms (for Stop-P3). In addition, peak amplitudes were also calculated for Go-N2 of correct go trials in time window of 200-330ms. According to the scalp distributions of each ERPs component, we focused on the frontal and central electrodes (Fz, Cz) for Stop-N2 and Go-N2, and additional parietal electrodes (Fz, Cz, Pz) for Stop-P3. Latency of each ERPs component was acquired where largest amplitudes were quantified, namely Fz for Stop-N2 and Go-N2, and Cz for Stop-P3. Stop-N2 ERPs were analyzed with a 3 (group: AOs, ROs, $\mathrm{HCs}) \times 2$ (trial type: SI, FI) $\times 2$ (electrodes: $\mathrm{Fz}, \mathrm{Cz}$ ) mixed repeated-measures ANOVA with trial type and electrodes as within-subjects factors while Stop-P3 were analyzed with a $3 \times 2 \times$ 3 (electrodes: Fz, Cz, Pz) mixed repeated-measures ANOVA. For Go-N2, a 3 (group: AOs, ROs, $\mathrm{HCs}) \times 2$ (electrodes: $\mathrm{Fz}, \mathrm{Cz}$ ) repeated-measures ANOVA was conducted. Latency data of Stop-N2 and Stop-P3 were analyzed with 3(group: AOs, ROs, HCs) $\times 2$ (trial type: SI, FI) mixed repeated measures ANOVA, while Go-N2 latency data was submitted to one-way ANOVA (group: AOs, ROs, HCs).

If the dataset deviated from sphericity, statistical analyses were conducted with the Greenhouse-Geisser correction for degrees of freedom. Post hoc t-tests with a Bonferroni adjustment for $p$ values were used. For all analyses, a $p$ value below .05 was considered significant.

\section{Results}

\subsection{Demographic and clinical variables}

The demographic and clinical characteristics of the participants for the behavioral (whole) sample and ERP (subset) sample are summarized for each experimental group (i.e., AO, RO, and 
HC) in Table 1. Note that the groups were well-matched in terms of age, gender, and education.

The AO and RO groups were also similar in terms of OCD symptom severity and age of onset.

However, BDI, STAI-S, and STAI-T scores differed between the three groups, with both clinical groups having higher scores than HCs on all three measures, but similar scores to each other.

Table 1 Demographic and clinical variables for the behavioral (whole) and ERP (subset) samples.

\begin{tabular}{lccccc}
\hline Sample & & & & & \\
\hline Behavioral & AO $(\mathbf{N}=\mathbf{4 2})$ & $\mathbf{R O}(\mathbf{N}=\mathbf{5 5})$ & $\mathbf{H C}(\mathbf{N}=\mathbf{6 2})$ & $\boldsymbol{F} / \boldsymbol{t} / \boldsymbol{\chi}^{\mathbf{2}}$ & $\boldsymbol{p}$ \\
Age (years) & $20.36(4.68)$ & $22.37(8.77)$ & $20.31(1.96)$ & 2.02 & .136 \\
Sex (female, \%) & $18(42.9)$ & $21(38.9)$ & $24(38.7)$ & 0.28 & .868 \\
Education (years) & $11.76(2.91)$ & $11.68(2.68)$ & $12.67(2.23)$ & 2.37 & .097 \\
Age at onset & $17.11(4.14)$ & $18.42(8.50)$ & - & -0.76 & .448 \\
Y-BOCS obsession score & $15.86(3.85)$ & $16.02(3.24)$ & - & -0.22 & .824 \\
Y-BOCS compulsion score & $14.90(4.15)$ & $14.56(4.27)$ & - & -0.40 & .688 \\
Y-BOCS total score & $30.76(7.35)$ & $30.57(6.83)$ & - & 0.13 & .897 \\
STAI-T & $49.00(5.07)$ & $47.41(5.56)$ & $41.51(6.56)$ & 23.08 & $<.001$ \\
STAI-S & $44.95(6.80)$ & $43.09(5.81)$ & $38.55(8.11)$ & 11.00 & $<.001$ \\
BDI & $23.19(11.61)$ & $22.26(10.88)$ & $7.11(5.24)$ & 47.23 & $<.001$ \\
ERPs & $\mathbf{A O}(\mathbf{N}=\mathbf{2 5})$ & $\mathbf{R O}(\mathbf{N}=\mathbf{2 5})$ & $\mathbf{H C}(\mathbf{N}=\mathbf{3 1})$ & $\boldsymbol{F} / \boldsymbol{t} / \boldsymbol{\chi}^{\mathbf{2}}$ & $\boldsymbol{p}$ \\
Age (years) & $20.07(4.40)$ & $20.48(4.15)$ & $21.96(2.58)$ & 1.46 & .241 \\
Sex (female, \%) & $8(32.0)$ & $8(32.0)$ & $12(38.7)$ & 0.38 & .827 \\
Education (years) & $11.93(2.04)$ & $11.95(1.80)$ & $13.08(2.23)$ & 2.27 & .112 \\
Age at onset & $17.08(4.70)$ & $16.76(4.36)$ & - & 0.20 & .844 \\
Y-BOCS obsession score & $16.44(4.11)$ & $16.00(2.89)$ & - & 0.39 & .698 \\
Y-BOCS compulsion score & $15.50(4.27)$ & $14.22(4.01)$ & - & 0.96 & .345 \\
Y-BOCS total score & $31.94(7.91)$ & $30.22(5.49)$ & - & 0.80 & .427 \\
STAI-T & $49.93(5.55)$ & $49.04(5.12)$ & $40.00(9.32)$ & 12.25 & $<.001$ \\
STAI-S & $45.20(7.58)$ & $43.70(6.49)$ & $35.82(11.76)$ & 6.28 & $<.01$ \\
BDI & $24.44(10.57)$ & $22.35(10.88)$ & $7.75(7.40)$ & 19.45 & $<.001$ \\
\hline Men with & & & &
\end{tabular}

Means with standard deviations in parentheses.

AO, autogenous obsessions group; RO, reactive obsessions group; HC, healthy control group; Y-BOCS, Yale-Brown Obsessive-Compulsive Scale; STAI-T, Spielberger State-Trait Anxiety Inventory-Trait Form; STAI-S, Spielberger State-Trait Anxiety Inventory-State Form; BDI, Beck Depression Inventory.

Significant post hoc tests for behavioral sample: STAI-T: AO > HC $(p<.001)$, RO > HC $(p<.001)$; STAI-S: AO > $\mathrm{HC}(p<.001), \mathrm{RO}>\mathrm{HC}(p=.001)$; BDI: $\mathrm{AO}>\mathrm{HC}(p<.001), \mathrm{RO}>\mathrm{HC}(p<.001)$.

Significant post hoc tests for ERP sample: STAI-T: AO > HC $(p<.001), \mathrm{RO}>\mathrm{HC}(p<.001)$; STAI-S: AO > HC $(p<.01), \mathrm{RO}>\mathrm{HC}(p<.01)$; $\mathrm{BDI}: \mathrm{AO}>\mathrm{HC}(p<.001), \mathrm{RO}>\mathrm{HC}(p<.001)$. 


\subsection{Emotional Stroop task}

The EST behavioral data are summarized in Table 2. For RT, the ANOVA revealed a main effect of group $\left(F_{2,156}=5.22, p<.01, \eta_{p}^{2}=0.063\right)$, owing to general slower RTs in the AO group ( $478.50 \pm 14.33 \mathrm{~ms})$ compared to the RTs in the RO $(422.86 \pm 12.53 \mathrm{~ms} ; p<.01$, Cohen's $d=4.13)$ and HC (426.21 $\pm 11.80 \mathrm{~ms} ; p<.01$, Cohen's $d=3.98)$ groups. There was not main effect of word type $\left(F_{2,156}=0.440, p=.644\right)$, but there was a significant group $\times$ word type interaction $\left(F_{2,156}=\right.$ 3.59, $\left.p<.01, \eta_{p}^{2}=0.044\right)$. Simple effects analysis revealed that the AO group's mean RT for negative words was longer than that for positive words ( $p<.05$, Cohen's $d=0.26)$ and showed a trend toward being longer than mean RT for neutral words ( $p=.055$, Cohen's $d=0.16$ ).

One-way ANOVAs indicated that there were no group effect on negative interference, $\left(F_{2,156}\right.$ $=1.64, p=.197)$, or on positive interference $\left(F_{2,156}=2.60, p=.078\right)$.

Additionally, the ANOVA revealed a main effect of group $\left(F_{2,156}=5.91, p<.01, \eta_{p}^{2}=\right.$ $0.070)$ on accuracy, with more response errors being committed by the $\mathrm{AO}(82 \% \pm 0.02 ; p<.05$, Cohen's $d=-3.79)$ and RO $(82 \% \pm 0.01 ; p<.01$, Cohen's $d=-6.00)$ groups than by the HC group $(88 \% \pm 0.01)$. Meanwhile, there was a trend toward a main effect of word type on accuracy $\left(F_{2,156}\right.$ $=3.00, p=.051)$, and no group $\times$ word type interaction $\left(F_{4,156}=0.56, p=.692\right)$.

Furthermore, no significant correlations were detected between clinical variables and EST results (word RTs, negative interference) for either OCD group (all $p>.159$ ).

Mean P1, N1, P2, P3b, and N450 amplitudes for each EST condition are reported for each group in Table 3. Grand average ERPs waveforms for each condition by groups are shown in Fig.1, and topographical maps for each ERP component are shown in Fig.2.

Amplitude: For P1, main effect of word type was significant $\left(F_{2,78}=4.44, p<.05, \eta_{p}^{2}=\right.$ 
$0.051)$, indicating larger P1 amplitude of negative words $(1.12 \pm 0.21 \mu \mathrm{V})$ than neutral words $(0.73 \pm 0.19 \mu \mathrm{V})(p<.05$, Cohen's $d=1.95)$. Significant interaction of Group $\times$ Word type $\times$ Electrodes was detected, $\left(F_{8,78}=2.15, p<.05, \eta_{p}^{2}=0.050\right)$. Further simple effects analyses revealed that negative words elicited larger P1 amplitudes than neutral words in $\mathrm{AO}$ groups at $\mathrm{OZ}$ (negative: $1.72 \pm 0.48 \mu \mathrm{V}$, neutral: $0.96 \pm 0.43 \mu \mathrm{V}$, Cohen's $d=1.67$ ) and in $\mathrm{HCs}$ at $\mathrm{O} 2$ (negative: $1.25 \pm 0.38 \mu \mathrm{V}$, neutral: $0.57 \pm 0.36 \mu \mathrm{V}$, Cohen's $d=1.84$ ). For $\mathrm{P} 2$, there was significant main effect of group $\left(F_{2,78}=3.44, p<.05, \eta_{p}^{2}=0.072\right)$. The group effect was further qualified by a significant group $\times$ region interaction $\left(F_{2,78}=3.58, p<.05, \eta_{p}^{2}=0.074\right)$, indicating that $\mathrm{AO}$ group had larger P2 amplitudes $(11.21 \pm 0.59 \mu \mathrm{V})$ than HCs $(8.69 \pm 0.52 \mu \mathrm{V})(p<.01$, Cohen's $d$ $=4.53)$ at central electrode sites. Additionally, main effects of region $\left(F_{1,78}=11.73, p<.005, \eta_{p}^{2}\right.$ $=0.116)$, hemisphere $\left(F_{2,78}=23.67, p<.001, \eta_{p}^{2}=0.210\right)$, and interaction of region $\times$ hemisphere $\left(F_{2,78}=15.47, p<.001, \eta_{p}^{2}=0.148\right)$ for $\mathrm{P} 2$ were significant, indicating that $\mathrm{P} 2$ amplitude was largest in Fz electrode site $(10.79 \pm 0.43 \mu \mathrm{V})$. For P3, significant main effects of group $\left(F_{2,78}=7.49, p<.005, \eta_{p}^{2}=0.161\right)$ was detected, driven by AO group having significantly larger P3b amplitudes $(8.28 \pm 0.61 \mu \mathrm{V})$ than both RO group $(5.41 \pm 0.61 \mu \mathrm{V} ; p<.01$, Cohen's $d=$ 4.70) and HC group $(5.40 \pm 0.54 \mu \mathrm{V} ; p<.005$, Cohen's $d=5.00)$. P3b amplitudes did not differ between the $\mathrm{RO}$ and $\mathrm{HC}$ groups $(p=1.00)$. There were also significant main effect of hemisphere $\left(F_{2,78}=7.82, p<.005, \eta_{p}^{2}=0.091\right)$ and region $\times$ hemisphere interaction $\left(F_{2,78}=15.37, p<.001\right.$, $\eta_{p}^{2}=0.165$ ) for P3b, indicating that maximal P3b amplitude was detected at the midline parietal electrode $(7.58 \pm 0.43 \mu \mathrm{V})$. For $\mathrm{N} 450$, a significant region $\times$ hemisphere $\times$ group interaction was detected $\left(F_{4,78}=7.84, p<.05, \eta_{p}^{2}=0.062\right)$. Further simple effects analysis revealed that HCs had more negative N450 than AOs at Cz (AOs: $6.01 \pm 0.75 \mu \mathrm{V}$, HCs: $3.16 \pm 0.72 \mu \mathrm{V}$; Cohen's $d$ 
$=3.88$ ) and C4 (AOs: $5.41 \pm 0.56 \mu \mathrm{V}$, HCs: $3.41 \pm 0.54 \mu \mathrm{V}$; Cohen's $d=3.64$ ) electrode sites. Main effects of region $\left(F_{1,78}=54.71, p<.001, \eta_{p}^{2}=0.381\right)$, hemisphere $\left(F_{2,78}=8.63, p<.001\right.$, $\left.\eta_{p}^{2}=0.088\right)$, and interaction between them $\left(F_{1,78}=10.99, p<.001, \eta_{p}^{2}=0.110\right)$ were also significant for $\mathrm{N} 450$, revealing that $\mathrm{N} 450$ was most negative at Fz electrode site $(2.54 \pm 0.42 \mu \mathrm{V})$.

Latency: For P1, main effect of word type was significant $\left(F_{2,164}=3.42, p<.05, \eta_{p}^{2}=\right.$ 0.038), and this was further explained by a significant group $\times$ word type interaction $\left(F_{4,164}=2.85\right.$, $\left.p<.05, \eta_{p}^{2}=0.062\right)$, indicating shorter latency of negative words $(71.54 \pm 5.60 \mathrm{~ms})$ than positive words $(87.88 \pm 5.47 \mathrm{~ms})$ in AOs $(p<.05$, Cohen's $d=-2.95)$. For N1, there were significant main effect of word type $\left(F_{2,78}=4.52, p<.05, \eta_{p}^{2}=0.116\right)$, driven by shorter latency of negative words $(134.61 \pm 3.45 \mathrm{~ms})$ than neutral words $(143.28 \pm 3.31 \mathrm{~ms})(p<.05$, Cohen's $d=-2.56)$, and main effect of group $\left(F_{2,78}=3.65, p<.05, \eta_{p}^{2}=0.050\right)$, with shorter latencies in AO (131.45 \pm $5.49 \mathrm{~ms})$ and RO $(132.19 \pm 4.81 \mathrm{~ms})$ groups than HCs $(149.96 \pm 4.82 \mathrm{~ms})$ (AOs $v s$. HCs: $p<.05$, Cohen's $d=-3.58$; ROs $v s$. HCs: $p<.05$, Cohen's $d=-3.69$ ). For P2, main effect of group was significant $\left(F_{2,78}=10.15, p<.001, \eta_{p}^{2}=0.191\right)$, indicating that AO $(196.46 \pm 4.59 \mathrm{~ms})$ and RO $(189.70 \pm 4.51 \mathrm{~ms})$ groups had longer P2 latencies than HCs $(170.87 \pm 3.90 \mathrm{~ms})$ (AOs $v s$. HCs: $p$ $<.05$, Cohen's $d=6.01 ;$ ROs $v s$. HCs: $p<.05$, Cohen's $d=4.47$ ). 
Table 2 Behavioral performance on the EST and SST.

\begin{tabular}{lccccc}
\hline Task variable & AO & RO & HC & $\boldsymbol{F}$ & $\boldsymbol{p}$ \\
\hline EST & $(\mathrm{N}=42)$ & $(\mathrm{N}=55)$ & $(\mathrm{N}=62)$ & & \\
Negative word accuracy & $82 \%(0.02)$ & $82 \%(0.01)$ & $88 \%(0.01)$ & - & - \\
Positive word accuracy & $82 \%(0.02)$ & $83 \%(0.02)$ & $88 \%(0.01)$ & - & - \\
Neutral word accuracy & $81 \%(0.02)$ & $80 \%(0.02)$ & $87 \%(0.02)$ & - & - \\
Negative word RT, ms & $491.33(99.03)$ & $422.33(117.11)$ & $420.71(65.07)$ & - & - \\
Positive word RT, ms & $467.70(84.62)$ & $421.83(112.47)$ & $435.51(91.07)$ & - & - \\
Neutral word RT, ms & $476.48(89.80)$ & $424.43(125.15)$ & $422.42(81.81)$ & - & - \\
Negative interference & $14.85(51.56)$ & $-2.10(43.24)$ & $-1.71(57.61)$ & 1.64 & .197 \\
Positive interference & $-8.78(43.20)$ & $-2.60(50.89)$ & $13.09(56.44)$ & 2.60 & .078 \\
\hline SST & $(\mathrm{N}=40)$ & $(\mathrm{N}=47)$ & $(\mathrm{N}=58)$ & $F_{2,142}$ & $p$ \\
GoRTs, ms & 600.30 & 620.07 & 661.39 & 2.34 & .100 \\
& $(163.34)$ & $(142.38)$ & $(130.62)$ & & \\
GoRTs SD & $230.56(74.25)$ & $245.39(68.97)$ & $258.87(53.32)$ & 2.20 & .115 \\
Correct Go trials, \% & $0.91(0.07)$ & $0.90(0.07)$ & $0.90(0.06)$ & 0.38 & .689 \\
$P(\mathrm{i})$ & $0.60(0.07)$ & $0.60(0.08)$ & $0.63(0.06)$ & 2.19 & .116 \\
SSRT, ms & $216.25(32.06)$ & $216.91(45.82)$ & $199.86(28.66)$ & 3.78 & .025 \\
SSD,ms & 384.04 & 403.16 & 461.53 & 3.50 & .033 \\
& $(169.72)$ & $(164.50)$ & $(130.71)$ & & \\
\hline
\end{tabular}

Means with standard deviations in parentheses.

$\mathrm{AO}$, autogenous obsessions group; $\mathrm{RO}$, reactive obsessions group; $\mathrm{HC}$, healthy control group

RT, reaction time; negative interference $=\mathrm{RT}$ in negative condition minus RT in neutral condition; positive interference $=\mathrm{RT}$ in positive condition minus RT in neutral condition; $p(\mathrm{i})$, probability of inhibition; SSRT, stop-signal reaction time, SSD: stop-signal delay.

Significant post hoc tests: SSRT: AOs > HC ( $p=.028)$, ROs > HC ( $p=.017)$; SSD: AOs < HC $(p=.046)$.

Table 3 ERPs amplitudes for negative, positive, and neutral words by group in EST.

\begin{tabular}{lccccccccc}
\hline \multirow{2}{*}{$\begin{array}{c}\text { ERP } \\
\text { Cmpt }\end{array}$} & \multicolumn{7}{c}{ EO $(\mathrm{N}=25)$} & \multicolumn{3}{c}{ RO $(\mathrm{N}=25)$} \\
\cline { 2 - 10 } & Negative & Positive & Neutral & Negative & Positive & Neutral & Negative & Positive & Neutral \\
\cline { 2 - 10 } P1 & 1.37 & 1.18 & 1.00 & 1.00 & 0.83 & 0.70 & 0.98 & 0.91 & 0.47 \\
& $(0.38)$ & $(0.39)$ & $(0.34)$ & $(0.36)$ & $(0.37)$ & $(0.32)$ & $(0.33)$ & $(0.34)$ & $(0.30)$ \\
N1 & -4.71 & --4.96 & -5.00 & -5.30 & -5.26 & -5.32 & -4.30 & -4.69 & -4.80 \\
& $(0.60)$ & $(0.62)$ & $(0.59)$ & $(0.58)$ & $(0.60)$ & $(0.57)$ & $(0.50)$ & $(0.52)$ & $(0.50)$ \\
P2 & 11.37 & 11.46 & 11.05 & 9.75 & 10.01 & 9.96 & 9.61 & 9.28 & 9.07 \\
& $(0.62)$ & $(0.63)$ & $(0.60)$ & $(0.60)$ & $(0.61)$ & $(0.58)$ & $(0.54)$ & $(0.54)$ & $(0.52)$ \\
P3b & 8.42 & 8.20 & 8.07 & 5.36 & 5.45 & 5.42 & 5.34 & 5.44 & 5.43 \\
& $(0.64)$ & $(0.69)$ & $(0.68)$ & $(0.64)$ & $(0.69)$ & $(0.68)$ & $(0.57)$ & $(0.62)$ & $(0.61)$ \\
N450 & 4.85 & 4.97 & 4.70 & 4.14 & 3.76 & 4.00 & 3.05 & 2.64 & 2.88 \\
& $(0.70)$ & $(0.65)$ & $(0.65)$ & $(0.79)$ & $(0.73)$ & $(0.73)$ & $(0.67)$ & $(0.62)$ & $(0.62)$ \\
\hline
\end{tabular}

$\mathrm{Cmpt}$, component; $\mathrm{AO}$, autogenous obsessions group; $\mathrm{RO}$, reactive obsessions group; $\mathrm{HC}$, healthy control group. 
Fig. 1. Grand average ERP waveforms of negative, positive, and neutral words for AOs, ROs, and HCs in EST.
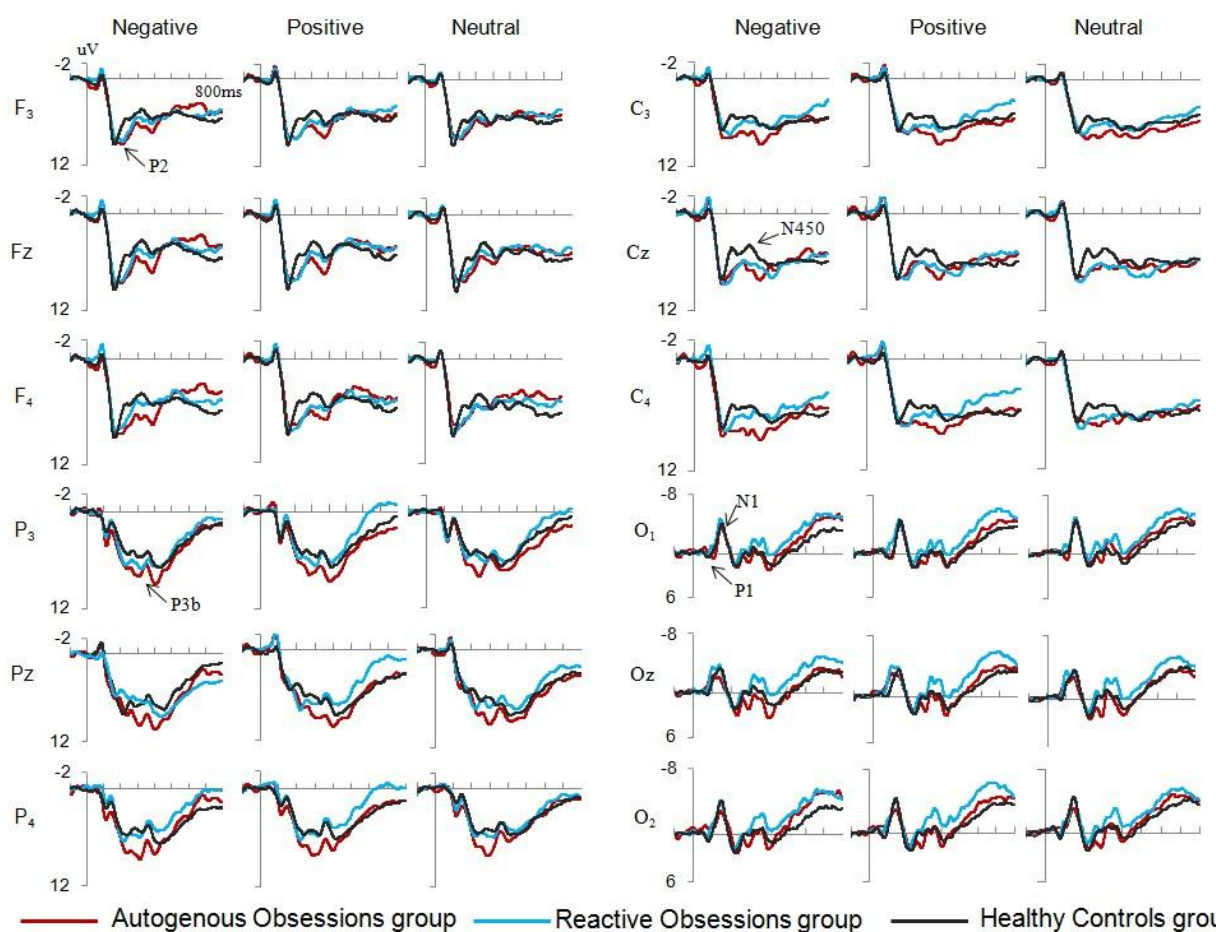

Fig.2. Topographical maps for each ERP component under each condition of AOs, ROs and HCs in EST.

AO Negative Positive Neutral P1

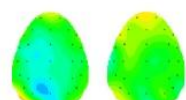

Negative Positive Neutral

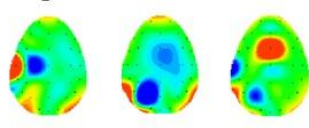

Negative Positive Neutral

$$
\text { N1 }
$$$$
\text { 90-130ms }
$$
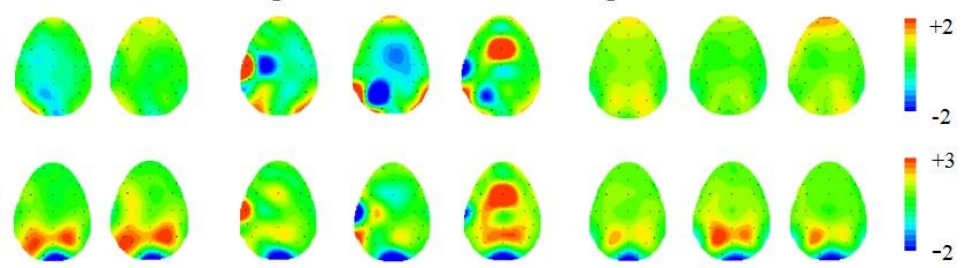

$\underset{180-250}{\text { P2 }}$
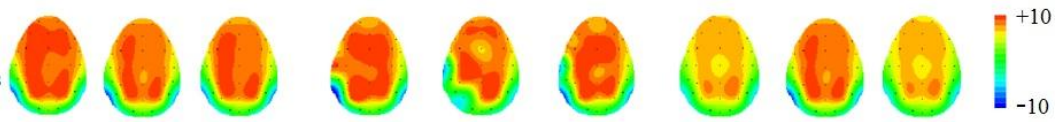

P3b

$280-400 \mathrm{~ms}$
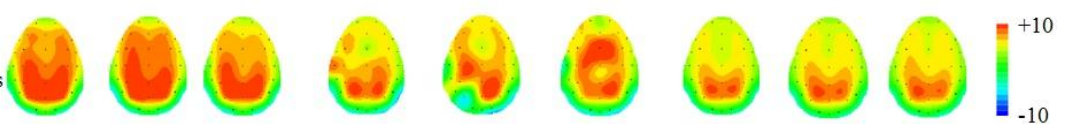

N450

300-450ms
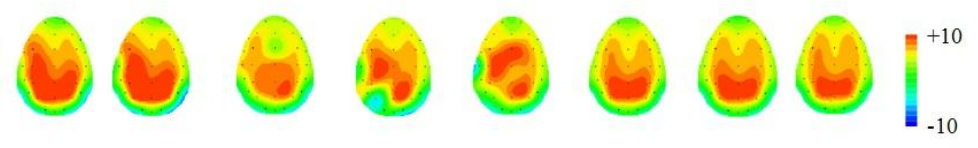


\subsection{SST}

The SST behavioral data are given in Table 2. For behavioral data, fourteen participants (2 AO, $8 \mathrm{RO}$, and $4 \mathrm{HC}$ ) were excluded from the final analysis because their $P(\mathrm{i})$ values were outside of the $25-75 \%$ range. A main effect of group was obtained for $\operatorname{SSRT}\left(F_{2,142}=3.78, p<.05, \eta_{p}^{2}=\right.$ 0.051), with both the AO ( $p<.05$, Cohen's $d=0.54)$ and RO ( $p<.05$, Cohen's $d=0.47)$ groups having longer mean SSRTs than the HC group. The three groups did not differ significantly in terms of $\operatorname{GoRT}\left(F_{2,142}=2.34, p=.100\right), \operatorname{SD}$ of $\operatorname{GoRTs}\left(F_{2,142}=2.20, p=.115\right)$, percent correct go trails $\left(F_{2,142}=0.38, p=.688\right)$, or percent successful inhibition stop trials, $\left(F_{2,142}=2.19, p=.116\right)$.

Neither SSRTs nor the number of correct responses on go trials correlated with any of the clinical variables (BDI, Y-BOCS, or STAI scores) examined in the AO and RO groups (all $p>.100)$.

In terms of ERPs data, prior to the final analysis, 12 participants ( $3 \mathrm{AO}, 5 \mathrm{RO}$, and $4 \mathrm{HC}$ ) were excluded for having fewer than 30 failed trials. The grand average ERPs and mean Stop-N2, Stop-P3, and Go-N2 amplitudes by group are shown in Fig. 3. Topographical maps for each ERP component are displayed in Fig.4.

Amplitudes: For Stop-N2, significant main effects of trial type $\left(F_{1,66}=42.89, p<.001, \eta_{p}^{2}\right.$ $=0.380)$ was found, driven by enhanced (more negative) Stop-N2 amplitudes in failed $(0.09 \pm$ $0.14 \mu \mathrm{V})$ than in successful inhibitions $(1.07 \pm 0.18 \mu \mathrm{V})$. For Stop-P3, significant main effects of trial type $\left(F_{1,66}=70.18, p<.001, \eta_{p}^{2}=0.515\right)$, electrodes $\left(F_{2,66}=20.56, p<.001, \eta_{p}^{2}=0.238\right)$, and significant trial type $\times$ electrode site interaction $\left(F_{2,66}=3.85, p<.05, \eta_{p}^{2}=0.055\right)$ were detected, indicating that successful inhibitions $(2.81 \pm 0.19 \mu \mathrm{V})$ elicited larger Stop-P3 amplitudes 
than failed inhibitions $(1.53 \pm 0.17 \mu \mathrm{V})$, and Stop-P3 amplitudes were most prominent at the $\mathrm{Cz}$ electrode site during the successful inhibition condition (Cz: $3.30 \pm 0.23 \mu \mathrm{V})$. Notably, significant trial type $\times$ group interaction was found $\left(F_{4,66}=5.93, p<.01, \eta_{p}^{2}=0.152\right)$, revealing that during successful inhibition, HCs $(3.57 \pm 0.31 \mu \mathrm{V})$ had larger Stop-P3 amplitudes than both AOs $(2.44 \pm$ $0.34 \mu \mathrm{V}: p<.05$, Cohen's $d=3.47)$ and ROs $(2.40 \pm 0.35 \mu \mathrm{V} ; p<.05$, Cohen's $d=3.54)$. For Go-N2, no significant main effects of group $\left(\mathrm{F}_{2,66}=1.34, p=.269\right)$, electrode $\left(\mathrm{F}_{1,66}=1.15, p\right.$ $=.287)$ or interaction effect $\quad\left(\mathrm{F}_{2,66}=0.89, p=.916\right)$ between them were detected.

Latency: For Stop-N2, main effect of trial type was detected $\left(F_{1,66}=4.26, p<.05, \eta_{p}^{2}=\right.$ 0.057), with longer latency in failed inhibition condition $(217.08 \pm 3.73 \mathrm{~ms})$ than in successful inhibition condition $(207.87 \pm 3.39 \mathrm{~ms})$. For Stop-P3, main effects of trail type was marginally significant, $\left(\mathrm{F}_{1,70}=3.90, p=.052\right)$, with slightly longer Stop-P3 latency in successful inhibition condition $(317.19 \pm 3.93 \mathrm{~ms})$ than in the failed inhibition condition $(307.46 \pm 4.61 \mathrm{~ms})$. Latency of Go-N2 ERPs component was not different among three groups $\left(\mathrm{F}_{2,68}=0.84, p=.436\right)$.

To better isolate the ERPs results of SST, we performed two different complementary analyses. First, we conducted an additional peak-to-peak analysis for Stop-N2 component at Fz electrode of SI condition. Second, we evaluated the relationship between Stop-P3 latency and SSRT in each group. Results showed that P2-N2 peak to peak amplitudes difference of SI at Fz were not differed among AOs $(1.69 \pm 1.28 \mu \mathrm{V})$, ROs $(1.55 \pm 0.87 \mu \mathrm{V})$ and $\mathrm{HCs}((1.93 \pm 1.41 \mu \mathrm{V}))$ $\left(\mathrm{F}_{2,72}=0.63, p=.535\right)$ and no significant correlations between Stop-P3 latency and SSRT for each group (all $p>.139)$. 
Fig. 3. ERP findings during SST performance. (A) Grand average ERP waveforms of SI, FI, and correct-go trials for AOs, ROs, and HCs. (B) Mean Stop-N2 as well as Stop-P3 amplitudes of SI and FI trials, and mean amplitude of Go-N2 for AOs, ROs, and HCs.

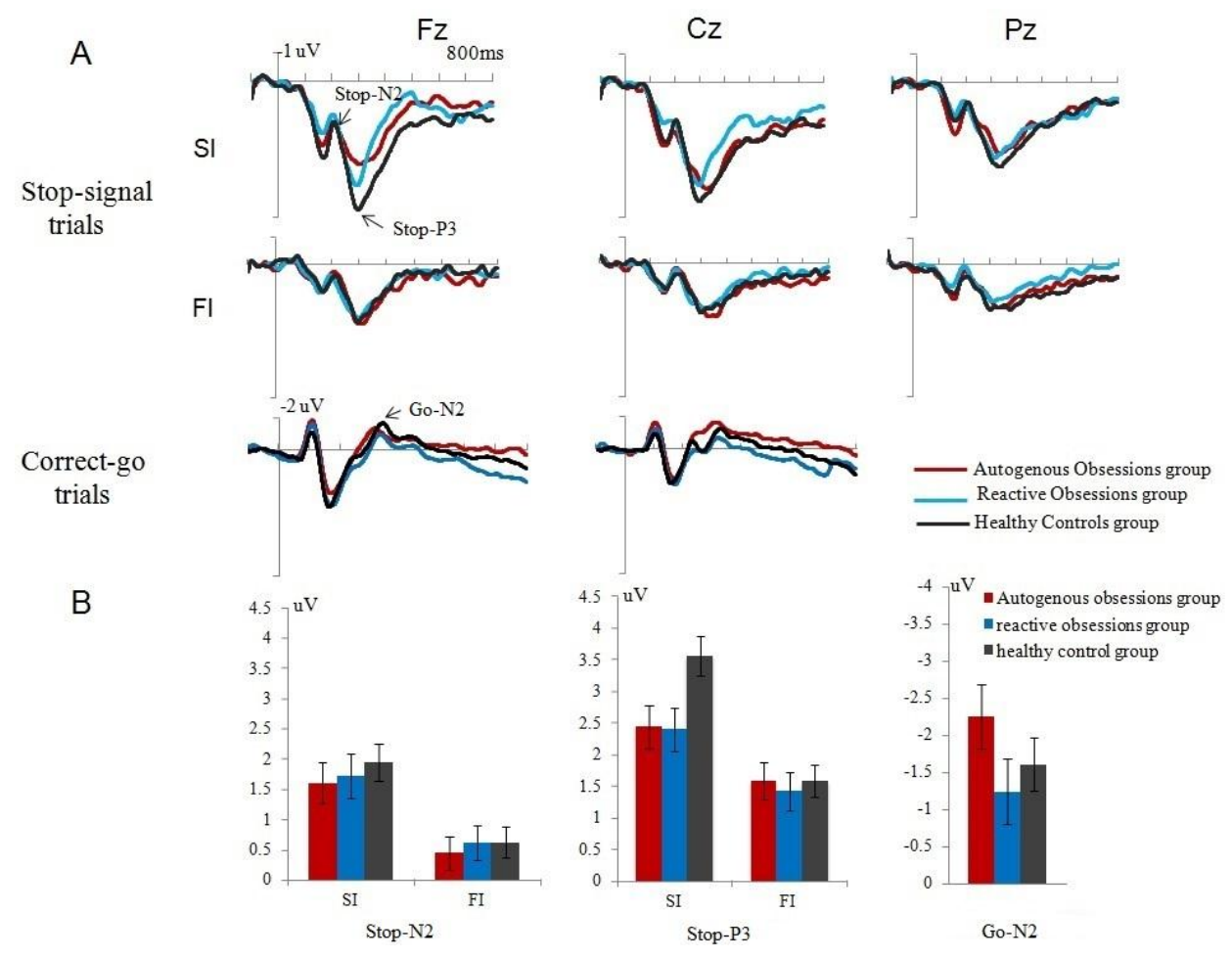

Fig. 4. Topographical maps for each ERP component by groups in SST.

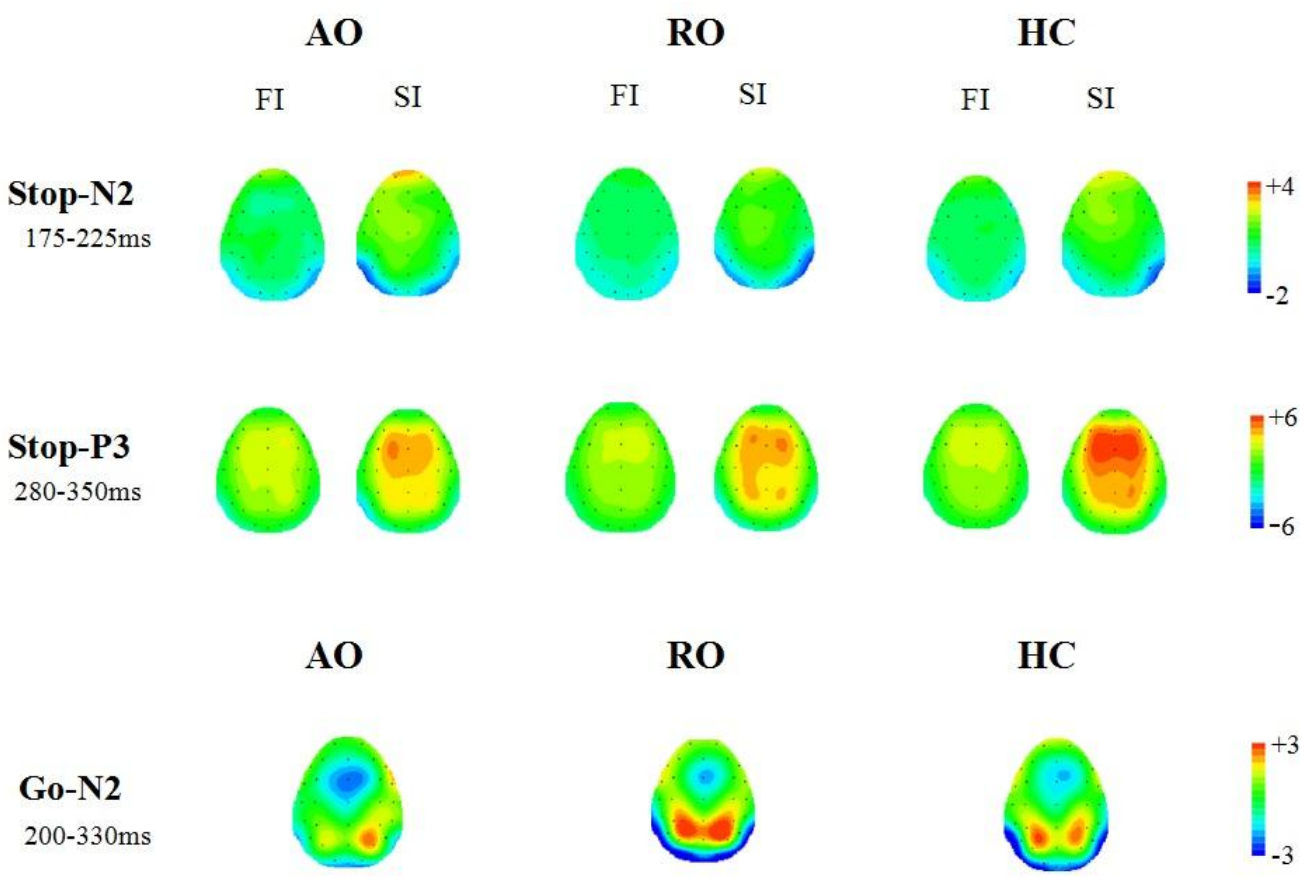




\section{Discussion}

Our study was designed to test the hypothesis that heterogeneity, specifically the autogenous-reactive OCD types, can account for the inconsistent results in studies of inhibition of OCD patients. To do this, we systematically compared the behavioral performance and electrophysiological mechanism of two components of inhibition, namely interference control and behavioral inhibition between AOs and ROs by using the EST and SST. Our results showed that, regarding the EST, both AOs and ROs committed more errors than control subjects, while only the AO patients had RTs longer than that of controls for color-naming all three types of words. Slower color-naming RTs for the negative words versus the neutral words were only revealed in the AO group. For ERPs data, negative words elicited larger P1 amplitude and shorter P1 latency than neutral words in AO group, and shorter N1 latency across three groups. The AO group had larger P3 amplitudes than both ROs and HCs and enhanced P2 and reduced N450 amplitudes than HCs independent of word type. Regarding the SST, both patient groups had longer SSRTs and reduced stop-P3 amplitudes in successful inhibition trials relative to HCs. To conclude, our results suggested that OCD patients of both types showed a behavioral inhibition impairment, which might be due to less effective or weaker activation of an inhibition system, whereas interference control deficits might seem to be only apparent in the autogenous OCD patients, who appeared to have more difficulty inhibiting processing of task-irrelevant information. In addition, AOs had more pronounced negative biases than ROs and HCs. To our knowledge, this study represents the first examination of both ERPs and behavioral differences between autogenous and reactive OCD patients in cognitive inhibition in response to emotional stimuli. 


\subsection{Emotional Stroop task}

\subsubsection{Attentional bias}

Our results demonstrated that AOs displayed longer color-naming time to negative words than positive and neutral words, which were in line with our hypothesis suggesting a more pronounced negative bias in AOs. Correspondingly, negative words in AOs were associated with larger P1 amplitude and shorter P1 latency. The phenomenon that P1 had a valence effect has been shown in many studies (Smith et al., 2003; Carretié et al., 2004; van Hooff et al., 2008; Thomas et al., 2013). Such early effects might remind that the coarse discrimination of emotional valence/significance could emerge as early as $70-100 \mathrm{~ms}$ post-stimulus onsets. As P1 originates in extrastriate neurons in the visual cortex (Hillyard \& Anllo-Vento, 1998), this rapid threat evaluation process might mediate by other affect-processing brain areas such as amygdala, which is known to influence processing of threat-related stimulus in many brain regions, including the visual cortex (Rotshtein et al., 2010). Neuroimaging studies have displayed amygdala activity alterations in color-naming threat words, which may implicate the response regulation to irrelevant threats (Compton et al., 2003), and more direct evidence comes from the results of Rotshtein et al. (2010). They found that amygdala damage diminished ERPs fear effects (i.e., enhanced amplitudes for fearful versus neutral faces) in the time range of P1. Thus, our results of enhanced P1 amplitude and earlier P1 latency can indicate that pronounced negative bias of AOs may arise through their facilitated sensory capture to negative stimulus modulated by amygdala. In addition, prior neuroimaging studies have revealed an amygdala-hippocampal connectivity deficit in autogenous OCD patient (Besiroglu et al., 2011), which may also affect negative emotional processing (Donegan et al., 2003). Future studies are needed to examine whether these 
connectivity abnormalities can further influence the negative bias in autogenous-type OCD patients. However, it is important to note that, there was possibility that some of the words in EST could have induced relatively greater emotional responses in the AO group compared with the ROs and HCs. Hence the negative bias we found in AOs may possibly be on account of the experimental manipulation itself.

Our behavioral data did not suggest of emotional Stroop RT effects in HC or RO group. Many studies have used the EST to explore interference inhibition or negative bias in both non-clinic and clinic populations. Consistently, nearly all the studies of non-clinic samples reported altered electrophysiological activities to negative stimuli in the absence of detectable behavioral differences (Pérez-Edgar \& Fox, 2003; Thomas et al., 2007; van Hooff et al., 2008). This may be due to the less sensitivity of behavioral measures to Stroop interference in EST (Thomas et al., 2007). EST RT results in OCD patients have been very inconsistent. For example, some of the studies reported that OCD patients have been associated with enhanced negative interference (Rao et al., 2010), or general slowness (slower color-naming time to all the three types of words, Gao et al., 2012; da Victoria et al., 2012; Fan et al., 2014), while others found neither (Moritz et al., 2004; 2008). The previous EST studies with OCD patients have usually treated the patients as a monolithic group, and while the present work showed dissociation in the EST profiles of autogenous versus reactive OCD patients. Hence we may propose that sample heterogeneity can explain, at least in part, the inconsistencies among prior results. While, it's important to note that, our ERPs data did reveal some differences between the way that negative words and neutral words were processed, and thus negative words were characterized by shorter N1 latency, which indicated that a certain degree sensory biases to negative information might be 
a general evolutionary adaption among humans, however, in some clinic populations, such as in AOs, the negative biases were more pronounced.

\subsubsection{Interference control}

In the current study, we found that AOs displayed overall longer color-naming RTs, regardless of word type than ROs and HCs. In EST, as like in classical Stroop task (CST), two dimensions of the word stimuli were processed. One is the irrelevant dimension (the processing of word meaning), and the other is the relevant dimension (the processing of color-naming). Notably, these two dimensions were processed in parallel, and thus the word meaning processing could interfere with the color-naming processing (MacLeod, 1991; Zurrón et al, 2013). In this sense, our finding of extended color-naming RTs in the AO group may suggest their interference inhibition failure for processing task-irrelevant information. It's worth reminding that longer color-naming time in AOs was independent of word type, which implicated that the interference inhibition dysfunction in AOs might represent a more generalized deficit impedes upon various types of content (positive, negative, and neutral). General interference inhibition deficits limited to AOs were consistent with finding of previous studies (Lee et al., 2009; Lee and Telch, 2010). Notably, although Lee et al. (2009) used a Go/No-go task, as is common for assessments of behavioral inhibition, their task contained a response-set reversal component, which is sensitive to assessment of inhibition for distracter information. Thus, the significantly longer RT in the reversal set for autogenous patients found by Lee et al. (2009) may consistently reflect an inhibition dysfunction in the patients' interference control domain.

Correspondingly, we found that AOs were characterized by larger P3b amplitude than ROs 
and HCs, and larger P2 and N450 (less negative) amplitudes than HCs, also regardless of word type. This pattern of ERPs results may strength our insight into the mechanism of general interference inhibition deficits among AOs. P2 reflects brain activation in relatively early perceptual stages and is thought to be associated with classification processing, as serve as an index of the ease with which relevant information can be distinguished from the irrelevant (Crowley \& Colrain, 2004). Both P3b and N450 represent relatively later, high-level and more controlled cognitive processing stage. Studies have revealed that smaller P3b amplitudes and/or enhanced negativity of N450 amplitude were both associated with larger conflicts conditions in classical and emotional Stroop tasks (Zurrón et al., 2009, 2013; West \& Alain., 2000; Qiu et al., 2006). Moreover, researchers have argued that P3b may reflect the stimulus evaluation processing and be associated with the meaning or values of the stimulus, while N450 may mostly reflect the conflict resolution. Thus, our results of abnormalities of $\mathrm{P} 2, \mathrm{P} 3 \mathrm{~b}$ and $\mathrm{N} 450$ amplitudes in AOs suggest that their impaired interference inhibition function may due to the mechanisms that AOs have difficulties in distinguishing relevant information from the irrelevant during early stimulus classification process (indicated by larger P2), and difficulties in dismissing from the meaning (task-irrelevant information) processing during later stimulus evaluation process (indicated by larger P3b). Furthermore, AOs may have lower efficiency in later conflict resolution (indicated by reduced N450). In addition, there were studies addressing that P2, P3b and N450 amplitudes may be affected by valence processing. However, findings in ERPs of EST were quite inconsistent (Pérez-Edgar \& Fox, 2003; Thomas et al., 2007; van Hooff et al., 2008). This may be due to the different task requirements, as in EST, participants were instructed to not to attend to the word meaning information, while other tasks usually asked participants to response to the meaning or 
valence of the stimulus.

As we knew, AOs and ROs were distinguished by the category of their primary obsession and these two types were quite different in their developing and maintaining mechanism as well as clinical features. Autogenous obsessions tend to come abruptly into consciousness and thus AOs may need to focus more on the efforts to suppress or to expel intrusive unwanted thoughts. Reactive obsessions are frequently triggered by external stimuli, and ROs seems to be affected more by anxiety reduction psychological mechanism through compulsive behaviors (Lee \& Kown, 2003). Thus different maintaining strategy, specifically the more intentional attempts to suppress unwanted thoughts with its paradoxical effect of AOs may be an important contributor to their impaired interference control.

In our study, we used an emotional Stroop task to illustrate the interference inhibition among three groups. It's important to note the possibilities of confounding effects of emotional stimulus on inference control. However, in our results, except for P1, which results revealed enhanced amplitude for negative words than neutral words, suggesting a bias towards negative information, ANOVA on other ERPs components of EST (P2, P3b, N450) did not reveal any word type main effects or interaction effects involving word type, which indicated that the interference of emotional processing might mainly occur during the very early cognitive processing stage. AOs displayed inference inhibition difficulties compared with ROs and HCs as mainly indicated by larger P3 and reduced N450 amplitudes regardless of word type during a relatively later cognitive stage. Therefore, the conclusion that AOs displayed interference inhibition in our study may be valid. 


\subsection{Stop-signal task}

The present observation that both AOs and ROs exhibited longer SSRTs in the SST than controls suggests that the two patient groups have similar behavioral inhibition deficits. Our findings also revealed that SSD in controls were significantly longer than that of two patient groups. As in SST, SSRT was computed by subtracting the average SSD from mean correct GoRTs (Odlaug et al., 2010; Galimberti et al., 2012), and in the present study, correct GoRTs were not significantly differed among three groups, thus it might be not surprised that the SSD in HCs were longer than that of AOs and ROs. Unfortunately, using Go/No-go and reversal tasks, Lee et al. (2009) did not find evidence of behavioral inhibition deficits (as reflected by commission error rates) in either autogenous or reactive patient groups. However, they employed a 1:1 Go to No-go stimulus ratio, which may have rendered the task too easy to be sensitive to a deficit.

It's worthy to note that in the present study, we found that the mean SDs of GoRTs in HCs were larger than that of AOs and ROs, which indicated that in HCs, the variability of GoRTs within each subject was larger than that of two patient groups. In our SST procedure, though all the participants were asked to press the space button as quickly as they saw the black " $\mathrm{X}$ " (go stimuli) on the screen, they might still wait in some extent for the stop signal as it randomly followed in $30 \%$ of the trials. This response strategy of trade-off between miss of stop signal and fast correct-go response might also adjust within subject depending on the actual performance during the task, leading to the trial-to-trial RT fluctuations in SST. Hence, the larger trial-to-trial RT variability of HCs may just be a reflection of their relatively more frequent/ flexible adjustments in response strategies. To go further, this result might be in line with the implications of impaired cognitive flexibility in OCD patients (Chamberlain et al., 2007). Notably, previous 
studies have proposed that systematically increased intra-individual variability might associate with changes in neuronal integrity, for example by aging or psychiatric or neurological diseases (Hultsch et al., 2002; Macdonald et al., 2006), however, in the present study, as the subjects were age-matched healthy controls, the explanation of more flexible strategy modifications seemed to be more plausible. While it should be noted that this conclusions should be considered with more caution since this difference in the present study did not reach significant level.

For the ERPs, we observed larger Stop-N2 amplitude and longer Stop-N2 latency for FI trials than for SI trials, in agreement with prior studies (Ramautar et al., 2006; Shen et al., 2011, 2014). The Stop-N2 component has been associated with conflict detection and early cognitive processing in the implementation of inhibitory control (Nieuwenhuis et al., 2003; Luijten et al., 2014). Thus, it could be that the Stop-N2 is smaller in SI trials, relative to FI trials, because of there being lesser conflict when the subject overrides the go response successfully in the SI condition. On the other hand, SI trials elicited larger Stop-P3 amplitudes than FI trials, supporting the prior suggestion that Stop-P3 is related to acute inhibitory processing and whether the outcome of inhibition is successful (Ramautar et al., 2006; Shen et al., 2011, 2014; Luijten et al., 2014). Previous studies have proposed that Stop-P3 may play a linking/bridge role between stimulus and response (Verleger et al., 2005; 2014; Whitson et al., 2014). In our study, we further analyzed the relationship between the latency of Stop-P3 and SSRT by groups, but results revealed no significance. The response-related mechanisms related to Stop-P3 in SST need further exploration. It's interesting to note that in our study, latency of Go-N2 was much later than that of Stop-N2. This may due to the fact that in SST, participants may have weighted the miss of stop signal against the fast correct-go response. 
AOs and ROs displayed no differences in both the amplitude and latency for Go-N2 compared with HCs, which suggested their intact similar response preparation set. However, both the AO and RO patient groups in our study had Stop-N2 amplitudes similar to HCs, but had reduced Stop-P3 amplitudes, relative to $\mathrm{HCs}$, in SI trials. The proximity of the neural generators of Stop-P3 to motor and premotor cortices (Luijten et al., 2014) may be functionally important. Kok et al. (2004) suggested that Stop-P3 in association with successful inhibition trials may reflect the efficiency of inhibitory control in addition to reflecting stop-signal processing. If that view is correct, then the small Stop-P3 combined with a typical Stop-N2, as observed in both groups of OCD patients in this study, may indicate that although the inhibitory response to stop-signals can be generated, their resultant inhibition has low efficiency or that the activation of their acute inhibition systems is weak.

Results of prior behavioral-ERP studies in OCD patients employing SST and Go/No-go tasks have been inconsistent. For example, we observed reduced Stop-P3 amplitudes with unchanged Stop-N2 amplitudes in the SST in this study, whereas other researchers have reported enhanced, reduced, or unchanged N2 amplitudes and P3 amplitudes (Kim et al., 2007; Ruchsow et al., 2007; Wang et al., 2008; Thomas et al., 2014; Lei et al., 2015). Others have suggested that these inconsistencies could be due, at least to some extent, to methodological differences, including differences between patient samples and behavioral paradigms. Further studies are needed to clarify the electrophysiological mechanisms of behavioral inhibition in OCD patients.

As mentioned before, we found that both OCD groups showed longer SSRT than healthy controls, which indicated their common behavioral inhibition deficits. But also, in our samples, both AOs and ROs showed larger depression and anxiety scores than controls, which leads to the 
wonder that this effect may be confounded by other psychiatric characteristics. To clarify this, we did the correlation analysis between SSRT and BDI, SAI and TAI scores in AOs and ROs respectively and results revealed no significance. Moreover, Morein-Zamir et al. (2009) used the SST to compare the motor inhibition deficit between OCD patients with and without co-morbid depression and they found that OCD patients were characterized by motor inhibition deficit regardless of depression status. According to all these, implications of behavioral inhibition deficits in AOs and ROs may be reliable.

In a recent meta-analysis of SSRT studies, Lipszyc and Schachar (2010) obtained a robust effect size for a prolonged SSRT in OCD patients $(g=0.77)$. Also, studies have found that deficits of behavioral inhibition in OCD are independent of symptom severity and symptom dimensions (Lei et al., 2015). Furthermore, unaffected first-degree relatives of OCD patients have also been reported to have SSRT deficits (Chamberlain et al., 2007; de Wit et al., 2012). All these evidence, as well as our present findings that a longer SSRT, relative to HCs, was observed in OCD subjects independent of their type classifications (i.e. it was present in both the $\mathrm{AO}$ and $\mathrm{RO}$ groups) consistently support the notion that behavioral inhibition deficit (especially inhibitory control-SSRT) may represent an endophenotype for OCD.

\subsection{Limitations and conclusions}

This study is, to the best of our knowledge, the first behavioral-ERP study to produce a systematic and comparative description of interference and behavioral inhibition in autogenous and reactive OCD patients, but it has limitations. First, because we lacked an objective measurement for differentiating between autogenous and reactive patients, the possibility of a 
classification bias cannot be ruled out. To reduce this risk, the classification was carried out by consensus between two expert psychiatrists conducting independent evaluations. Second, we did not ask our participants to rate the emotional words after they finished the experiments. As in the present study, we did not find any valence difference in color-naming RTs in $\mathrm{HC}$ and RO groups. This may raise the concern that the valence does not play any role in this task at least in the two groups. Further ratings of our participants may at least partly help to illustrate this issue. Third, we used the EST to assess the interference inhibition, which carried the risks of confounding effects of emotional processing on interference control. Further studies using more classical measurements, such as classical Stroop tasks are welcomed. Finally, our ERPs set sample was relatively small, which may limit the interpretation of our findings. Further researches with larger sample size are needed to examine the hypotheses.

In conclusion, the present findings suggest that behavioral inhibition impairment may reflect a common pathology in both patients with autogenous or reactive obsessions, perhaps due to low-efficiency acute inhibition processing. On the other hand, our findings suggest that interference control impairment may be limited to autogenous-type OCD patients due to their specific difficulties in inhibiting processing task-irrelevant information and low efficiency of conflict resolution. 


\section{Acknowledgements}

This work was supported by National Science Foundation of China (Mingtian Zhong, grant number 81371487); and National Science Foundation for Young Scholars of China (Lin Cai, grant number 81401128). 


\section{References}

[APA] American Psychiatric Association. (2013). Diagnostic and Statistical Manual of Mental Disorders, Fifth Edition, Text Revision. American Psychiatric Association; Washington, DC.

Aydin, P. C., Koybasi, G. P., Sert, E., Mete, L., \& Oyekcin, D. G. (2014). Executive functions and memory in autogenous and reactive subtype of obsessive-compulsive disorder patients. Comprehensive psychiatry, 55(4), 904-911.

Band, G. P. H., Van der Molen, M. W., \& Logan, G. D. (2003). Horse-race model simulations of the stop-signal procedure. Acta Psychologica, 112(2), 105-142.

Bannon, S., Gonsalvez, C. J., Croft, R. J., \& Boyce, P. M. (2002). Response inhibition deficits in obsessive-compulsive disorder. Psychiatry research, 110(2), 165-174.

Beck, A. T., Ward, C. H., Mendelson, M., Mock, J., \& Erbaugh, J. (1961). An inventory for measuring depression. Archives of General Psychiatry, 4(6), 561-571.

Belloch, A., Morillo, C., Lucero, M., Cabedo, E., \& Carrió, C. (2004). Intrusive thoughts in non - clinical subjects: the role of frequency and unpleasantness on appraisal ratings and control strategies. Clinical Psychology \& Psychotherapy, 11(2), 100-110.

Belloch, A., Cabedo, E., Carrió, C., \& Larsson, C. (2010). Cognitive therapy for autogenous and reactive obsessions: clinical and cognitive outcomes at post-treatment and 1-year follow-up. Journal of anxiety disorders, 24(6), 573-580.

Besiroglu, L., Sozen, M., Ozbebit, Ö., Avcu, S., Selvi, Y., \& Bora, A. (2011). The involvement of distinct neural systems in patients with obsessive-compulsive disorder with autogenous and reactive obsessions. Acta Psychiatrica Scandinavica, 124(2), 141-151.

Besiroglu, L., Uguz, F., Ozbebit, O., Guler, O., Cilli, A. S., \& Askin, R. (2007). Longitudinal 
assessment of symptom and subtype categories in obsessive-compulsive disorder. Depression and Anxiety, 24(7), 461-466.

Carretié, L., Hinojosa, J. A., Martín - Loeches, M., Mercado, F., \& Tapia, M. (2004). Automatic attention to emotional stimuli: neural correlates. Human brain mapping, 22(4), 290-299.

Chamberlain, S. R., Blackwell, A. D., Fineberg, N. A., Robbins, T. W., \& Sahakian, B. J. (2005). The neuropsychology of obsessive compulsive disorder: the importance of failures in cognitive and behavioural inhibition as candidate endophenotypic markers. Neuroscience \& Biobehavioral Reviews, 29(3), 399-419.

Chamberlain, S. R., Fineberg, N. A., Menzies, L. A., Blackwell, A. D., Bullmore, E. T., Robbins, T. W., \& Sahakian, B. J. (2007). Impaired cognitive flexibility and motor inhibition in unaffected first-degree relatives of patients with obsessive-compulsive disorder. America Journal of Psychitry, 164(2), 335-8.

Compton, R. J., Banich, M. T., Mohanty, A., Milham, M. P., Herrington, J., Miller, G. A., Scalf, P. E., Webb, A., \& Heller, W. (2003). Paying attention to emotion: an fMRI investigation of cognitive and emotional stroop tasks. Cognitive Affective \& Behavioral Neuroscience, 3(2), $81-96$.

Congdon, E., Mumford, J., Cohen, J. R., Galvan, A., Poldrack, R., \& Canli, T. (2012). Measurement and reliability of response inhibition. Frontiers in Psychology, 3.

Crowley, K. E., \& Colrain, I. M. (2004). A review of the evidence for P2 being an independent component process: age, sleep and modality. Clinical neurophysiology, 115(4), 732-744.

da Victoria, M. S., Nascimento, A. L., \& Fontenelle, L. F. (2012). Symptom-specific attentional bias to threatening stimuli in obsessive-compulsive disorder. Comprehensive psychiatry, 
53(6) , 783-788.

de Wit, S. J., de Vries, F. E., van der Werf, Y. D., Cath, D. C., Heslenfeld, D. J., Veltman, E. M., van Balkom, A. J., Veltman, D. J., \& van den Heuvel, O. A. (2012). Presupplementary motor area hyperactivity during response inhibition: a candidate endophenotype of obsessive-compulsive disorder. American journal of psychiatry , 69(10), 1100-1108.

Dimoska, A., Johnstone, S. J., \& Barry, R. J. (2006). The auditory-evoked N2 and P3 components in the stop-signal task: indices of inhibition, response-conflict or error-detection?. Brain and cognition, 62(2), 98-112.

Donegan, N. H., Sanislow, C. A., Blumberg, H. P., Fulbright, R. K., Lacadie, C., Skudlarski, P., Gore, J. C., Olson, I. R., Mcglashan, T. H., \& Wexler, B. E. (2003). Amygdala hyperactivity in borderline personality disorder: implications for emotional dysregulation. Biological psychiatry ,54(11), 1284-1293.

Falkenstein, M., Hoormann, J., \& Hohnsbein, J. (1999). ERP components in Go/Nogo tasks and their relation to inhibition. Acta psychologica, 101(2), 267-291.

Falkenstein, M., Hoormann, J., \& Hohnsbein, J. (2002). Inhibition-Related ERP Components: Variation with Modality, Age, and Time-on-Task. Journal of Psychophysiology, 16(3), $167-175$.

Fan, J., Zhong, M., Zhu, X., Lei, H., Dong, J., Zhou, C., \& Liu, W. (2014). An attentional inhibitory deficit for irrelevant information in obsessive-compulsive disorder: Evidence from ERPs. International Journal of Psychophysiology, 94(3), 420-426.

Fauth-Bühler, M., de Rover, M., Rubia, K., Garavan, H., Abbott, S., Clark, L., Vollstädt-Klein, S., Mann, K., Schumann, G., \& Robbins, T. W. (2012). Brain networks subserving fixed versus 
performance-adjusted delay stop trials in a stop signal task. Behavioural brain research, 235(1), 89-97.

Finke, M., Barceló, F., Garolera, M., Cortinas, M., Garrido, G., Pajares, M., \& Escera, C. (2011). Impaired preparatory re-mapping of stimulus-response associations and rule-implementation in schizophrenic patients-The role for differences in early processing. Biological psychology, 87(3), 358-365.

Freunberger, R., Klimesch, W., Doppelmayr, M., \& Höller, Y. (2007). Visual P2 component is related to theta phase-locking. Neuroscience letters, 426(3), 181-186.

Friedman, D. (2000). Event-related brain potential investigations of memory and aging. Biological Psychology, 54(1), 175-206.

Frings, C., \& Groh-Bordin, C. (2007). Electrophysiological correlates of visual identity negative priming. Brain research, 1176, 82-91.

Gajewski, P. D., \& Falkenstein, M. (2013). Effects of task complexity on ERP components in Go/Nogo tasks. International Journal of Psychophysiology, 87(3), 273-278.

Gajewski, P. D., Stoerig, P., \& Falkenstein, M. (2008). ERP—correlates of response selection in a response conflict paradigm. Brain research, 1189, 127-134.

Galimberti, E., Martoni, R. M., Cavallini, M. C., Erzegovesi, S., \& Bellodi, L. (2012). Motor inhibition and cognitive flexibility in eating disorder subtypes. Progress in neuro-psychopharmacology and biological psychiatry, 36(2), 307-312.

Gao, L., Tao, R., \& Pang, B. (2012). Attentional bias in the individuals with obsessive-compulsive disorder. Journal of Clinical Psychiatry, 22, 783-788

Goodman, W. K., Price, L. H., Rasmussen, S. A., Mazure, C., Fleischmann, R. L., Hill, C. L., 
Heninger, G. R., \& Charney, D. S. (1989). The Yale-Brown obsessive compulsive scale: I. Development, use, and reliability. Archives of general psychiatry, 46(11), 1006-1011.

Gratton, G., Coles, M. G. H., \& Donchin, E. (1983). A new method for off-line removal of ocular artifact. Electroencephalography and clinical neurophysiology, 55(4), 468-484.

Hasler, G., LaSalle-Ricci, V. H., Ronquillo, J. G., Crawley, S. A., Cochran, L. W., \& Kazuba, D. (2005). Obsessive-compulsive disorder symptom dimensions show specific relationships to psychiatric comorbidity. Psychiatry Research, 135(2), 121-132.

He, L., Ewing, J., Shaw, A. M., Wang, J. P., \& Chasson, G. S. (2014). A cross-sectional investigation of autogenous and reactive obsessions and associated cognitive and symptom correlates in China. International journal of clinical and health psychology, 14(2): 93-101.

Herbert, C., Kissler, J., Junghöfer, M., Peyk, P., \& Rockstroh, B. (2006). Processing of emotional adjectives: evidence from startle EMG and ERPs. Psychophysiology, 43(2), 197-206.

Hillyard, S. A., \& Anllo-Vento, L. (1998). Event-related brain potentials in the study of visual selective attention. Proceedings of the National Academy of Sciences of the United States of America, 95(3), 781-787.

Holle, C., Neely, J. H., \& Heimberg, R. G. (1997). The effects of blocked versus random presentation and semantic relatedness of stimulus words on response to a modified Stroop task among social phobics. Cognitive Therapy and Research, 21(6), 681-697.

Hultsch, D. F., Macdonald, S. W. S., \& Dixon, R. A. (2002). Variability in reaction time performance of younger and older adults. Journals of Gerontology, 57(2), P101-15.

Iervolino, A.C., Rijsdijk, F. V., Cherkas, L., Fullana, M. A., \& Mataix-Cols, D. (2011). A multivariate twin st udy of obsessive-compulsive symptom dimensions. Archives of General 
Psychiatry, 68(6), 637-644.

Kang, D. H., Jang, J. H., Han, J. Y., Kim, J. H., Jung, W. H., Choi, J. S., Choi, C. H., \& Kwon, J. S. (2013). Neural correlates of altered response inhibition and dysfunctional connectivity at rest in obsessive-compulsive disorder. Progress in Neuro-Psychopharmacology and Biological Psychiatry, 40, 340-346.

Katerberg, H., Delucchi, K. L., Stewart, S. E., Lochner, C., Denys, D. A. J. P., Stach, D. D. E, Andresen, J. M., Grant, J. E., Kim, G. S. W., Williams, K. A., den Boer, J. A., van Balkom, A. J. L. M., Smit, J. H., van Oppen, S. P., Polman, A., Jenike, M. A., Stein, D. J., Mathews, C. A., \& Cath, D. C. (2010). Symptom Dimensions in OCD: Item-Level Factor Analysis and Heritability Estimates. Behavior Genetics, 40(4), 505-517.

Kim, M. S., Kim, Y. Y., Yoo, S. Y., \& Kown, J. S. (2007). Electrophysiological correlates of behavioral response inhibition in patients with obsessive-compulsive disorder. Depression and anxiety, 24(1), 22-31.

Kok, A., Ramautar, J. R., De Ruiter, M. B., and G. P., \& Ridderinkhof, K. B. (2004). ERP components associated with successful and unsuccessful stopping in a stop - signal task. Psychophysiology, 41(1), 9-20.

Kowalczyk, M. (2006). Cognitive inhibition and thought suppression in obsessive-compulsive disorder--a review. Psychiatria Polska, 40(6), 103-136.

Kwon, J. S., Kim, J. J., Lee, D. W., Lee, J. S., Lee, D, S., Kim, M. S., Lyoo, I. K., Cho, M. J., \& Lee, M. C. (2003). Neural correlates of clinical symptoms and cognitive dysfunctions in obsessive-compulsive disorder. Psychiatry Research: Neuroimaging, 122(1), 37-47.

Lee, H. J., \& Kwon, S. M. (2003). Two different types of obsession: autogenous obsessions and 
reactive obsessions. Behaviour Research and Therapy, 41(1), 11-29.

Lee, H. J., \& Telch, M. J. (2010). Differences in latent inhibition as a function of the autogenous-reactive OCD subtype. Behaviour research and therapy, 48(7), 571-579..

Lee, H. J., Kwon, S. M., Kwon, J. S., \& Telch, M. J. (2005a). Testing the autogenous-reactive model of obsessions. Depression and Anxiety, 21(3), 118-129.

Lee, H. J., Lee, S. H., Kim, H. S., Kwon, S. M., \& Telch, M. J. (2005b). A comparison of autogenous/reactive obsessions and worry in a nonclinical population: A test of the continuum hypothesis. Behaviour Research and Therapy, 43(8), 999-1010.

Lee, H. J., Yost, B. P., \& Telch, M. J. (2009). Differential performance on the go/no-go task as a function of the autogenous-reactive taxonomy of obsessions: Findings from a non-treatment seeking sample. Behaviour research and therapy, 47(4), 294-300.

Lei, H., Yi, J., Wang, H., Zhang, X., Dong, J., Zhou, C., Fan, J., Zhong, M., \& Zhu, X. (2013). Inhibitory deficit in semantic conflict in obsessive-compulsive disorder: An event-related potential study. Neuroscience letters, 552, 162-167.

Lei, H., Zhu, X., Fan, J., Dong, J., Zhou, C., Zhang, X., \& Zhong, M. (2015). Is impaired response inhibition independent of symptom dimensions in obsessive-compulsive disorder? Scientific Reports. 20. doi: 10.1038/srep10413.

Lipszyc, J., \& Schachar, R. (2010). Inhibitory control and psychopathology: a meta-analysis of studies using the stop signal task. Journal of the International Neuropsychological Society, 16(06), 1064-1076.

Logan, G. D., Cowan, W. B., \& Davis, K. A. (1984). On the ability to inhibit simple and choice reaction time responses: a model and a method. Journal of Experimental Psychology: Human 
Perception and Performance, 10(2), 276.

Logan, G.D., Schachar, R.J., \& Tannock, R. (1997). Impulsivity and inhibitory control. Psychological Science, 8, 60-4.

Lubow, R. E., \& Gewirtz, J. C. (1995). Latent inhibition in humans: data, theory, and implications for schizophrenia. Psychological bulletin, 117(1), 87.

Luck, S. J., Fan, S., \& Hillyard, S. A. (1993). Attention-related modulation of sensory-evoked brain activity in a visual search task. Cognitive Neuroscience, Journal of, 5(2), 188-195.

Luijten, M., Machielsen, M. W. J., Veltman, D. J., Hester, R., de Haan, L., \& Franken, I. H. (2014). Systematic review of ERP and fMRI studies investigating inhibitory control and error processing in people with substance dependence and behavioural addictions. Journal of psychiatry \& neuroscience: JPN, 39(3), 149-69.

Macdonald, S. W., Nyberg, L., \& Bäckman, L. (2006). Intra-individual variability in behavior: links to brain structure, neurotransmission and neuronal activity.. Trends in Neurosciences, $29(8), 474-480$.

Macleod, C. M. (1991). Half a century of research on the stroop effect: an integrative review.. Psychological Bulletin, 109(109), 163-203.

Maltby, N., Tolin, D. F., Worhunsky, P., O’Keefe, T. M., \& Kiehl, K. A. (2005). Dysfunctional action monitoring hyperactivates frontal-striatal circuits in obsessive-compulsive disorder: an event-related fMRI study. Neuroimage, 24(2), 495-503.

Mataix-Cols, D., Rauch, S. P., Manzo, P. A., Jenike, M. A., \& Baer, L. (1999). Use of factor-analyzed symptom dimensions to predict outcome with serotonin reuptake inhibitors and placebo in the treatment of obsessive-compulsive disorder. American Journal of 
Psychiatry, 156(9), 1409-16.

Mataix-Cols, D., Rosario-Campos, M. C., \& Leckman, J. F. (2005). A multidimensional model of obsessive-compulsive disorder. American Journal of Psychiatry, 162(2), 228-238.

Mataix-Cols, D., Wooderson, S., Lawrence, N., Brammer, M. J., Speckens, A., \& Phillips, M. L. (2004). Distinct neural correlates of washing, checking, and hoarding symptom dimensions in obsessive-compulsive disorder. Arch Gen Psychiatry, 61(6), 564-576.

McKay, D., Abramowitz, J. S., \& Taylor, S. (2008). Conceptualizing subtypes of obsessive-compulsive disorder. In J. Abramowitz, S. Taylor, \& D. McKay (Eds.), Obsessive-compulsive disorder: subtypes and spectrum conditions. New York: Elsevier.

Morein-Zamir, S., Fineberg, N.A., Robbins, T.W., \& Sahakian, B.J. (2009). Inhibition of thoughts and actions in obsessive-compulsive disorder: extending the endophenotype? Psychological Medicine, 40(2), 263-272.

Moritz, S., Fischer, B. K., Hottenrott, B., Kellner, M., Fricke, S., Randjar, S., \& Jelinek, L. (2008). Words may not be enough! No increased emotional Stroop effect in obsessive-compulsive disorder. Behaviour Research and Therapy, 46(9), 1101-1104.

Moritz, S., Jacobsen, D., Kloss, M., Fricke, S., Rufer, M., \& Hand, I. (2004). Examination of emotional Stroop interference in obsessive-compulsive disorder. Behaviour Research and Therapy, 42(6), 671-682.

Moulding, R., Kyrios, M., Doron, G., \& Nedeljkovic, M. (2007). Autogenous and reactive obsessions: Further evidence for a two-factor model of obsessions. Journal of Anxiety Disorders, 21(5), 677-690. 
Nieuwenhuis, S., Yeung, N., Van Den Wildenberg, W., \& Ridderinkhof, K. B. (2003). Electrophysiological correlates of anterior cingulate function in a go/no-go task: effects of response conflict and trial type frequency. Cognitive, affective, \& behavioral neuroscience, 3(1), 17-26.

Nigg, J. T. (2000). On inhibition/disinhibition in developmental psychopathology: views from cognitive and personality psychology and a working inhibition taxonomy. Psychological bulletin, 126(2), 220.

Odlaug, B. L., Chamberlain, S. R., \& Grant, J. E. (2010). Motor inhibition and cognitive flexibility in pathologic skin picking. Progress in neuro-psychopharmacology and biological psychiatry, 34(1), 208-211.

Penadés, R., Catalán, R., Andrés, S., Salamero, M., \& Gasto, C. (2005). Executive function and nonverbal memory in obsessive-compulsive disorder. Psychiatry research, 133(1), 81-90.

Pérez-Edgar, K., \& Fox, N. A. (2003). Individual differences in children's performance during an emotional Stroop task: A behavioral and electrophysiological study. Brain and Cognition, 52(1), 33-51.

Potts, G. F. (2004). An ERP index of task relevance evaluation of visual stimuli. Brain and cognition, 56(1), 5-13.

Purdon, C., \& Clark, D. A. (1993). Obsessive intrusive thoughts in nonclinical subjects. Part I. Content and relation with depressive, anxious and obsessional symptom. Behaviour research and therapy, 31(8), 713-720.

Purdon, C., \& Clark, D. A. (1994). Obsessive intrusive thoughts in nonclinical subjects. Part II. Cognitive appraisal, emotional response and thought control strategies. Behaviour Research 
and Therapy, 32(4), 403-410.

Qiu, J., Luo, Y., Wang, Q., Zhang, F., \& Zhang, Q. (2006). Brain mechanism of Stroop interference effect in Chinese characters. Brain Research, 1072(1), 186-193.

Ramautar, J. R., Kok, A., \& Ridderinkhof, K. R. (2006). Effects of stop-signal modality on the N2/P3 complex elicited in the stop-signal paradigm. Biological psychology, 72(1), 96-109.

Rao, N. P., Arasappa, R., Reddy, N. N., Venkatasubramanian, G., \& Reddy, Y. C. (2010). Emotional interference in obsessive-compulsive disorder: A neuropsychological study using optimized emotional Stroop test. Psychiatry research, 180(2), 99-104.

Rotshtein, P., Richardson, M. P., Winston, J. S., Kiebel, S. J., Vuilleumier, P., Eimer, M., Drive, J., \& Dolan, R. J. (2010). Amygdala damage affects event-related potentials for fearful faces at specific time windows. Human Brain Mapping, 31(7), 1089-1105.

Ruchsow, M., Reuter, K., Hermle, L., Ebert, D., Kiefer, M., \& Falkenstein, M. (2007). Executive control in obsessive-compulsive disorder: event-related potentials in a Go/Nogo task. Journal of Neural Transmission, 114(12), 1595-1601.

Shen, I. H., Lee, D. S., \& Chen, C. (2014). The role of trait impulsivity in response inhibition: Event-related potentials in a stop-signal task. International Journal of Psychophysiology, 91(2), 80-87.

Shen, I. H., Tsai, S. Y., \& Duann, J. R. (2011). Inhibition control and error processing in children with attention deficit/hyperactivity disorder: an event-related potentials study. International Journal of Psychophysiology, 81(1), 1-11.

Smith, N. K., Cacioppo, J. T., Larsen, J. T., \& Chartrand, T. L. (2003). May i have your attention, please: electrocortical responses to positive and negative stimuli. Neuropsychologia, 41(2), 
171-183.

Spielberger, D. C., Gorsuch, R. L., \& Lushene, R. (1983). Manual for the State-Trait Anxiety Inventory (Form Y) [M ]. Palo Alto:Consulting Psychologists Press, Inc.

Subirà, M., Alonso, P., Segalàs, C., Real, E., Lopez-Sola, C., Pujol, J., Martinez-Zalacain, I., Harrison, B. J., Menchon, J. M., Cardoner, N., \& Soriano-Mas, C. (2013). Brain Structural Alterations in Obsessive-Compulsive Disorder Patients with Autogenous and Reactive Obsessions. PloS one, 8(9), e75273.

Thomas, S. J., Gonsalvez, C. J., \& Johnstone, S. J. (2013). Neural time course of threat-related attentional bias and interference in panic and obsessive-compulsive disorders. Biological psychology, 94(1), 116-129.

Thomas, S. J., Gonsalvez, C. J., \& Johnstone, S. J. (2014). How specific are inhibitory deficits to obsessive-compulsive disorder? A neurophysiological comparison with panic disorder. Clinical Neurophysiology, 125(3), 463-475.

Thomas, S. J., Johnstone, S. J., \& Gonsalvez, C. J. (2007). Event-related potentials during an emotional Stroop task. International journal of psychophysiology, 63(3), 221-231.

van Hooff, J. C., Dietz, K. C., Sharma, D., \& Bowman, H. (2008). Neural correlates of intrusion of emotion words in a modified Stroop task. International Journal of Psychophysiology, 67(1), 23-34.

van Velzen, L. S., Vriend, C., de Wit, S. J., \& van den Heuvel, O. A. (2014). Response inhibition and interference control in obsessive-compulsive spectrum disorders. Frontiers in Human Neuroscience, 8.

Verleger, R., Jaśkowski, P., \& Wascher, E. (2005). Evidence for an integrative role of P3b in 
linking reaction to perception. Journal of Psychophysiology, 19(3), 165-181.

Verleger, R., Metzner, M.F., Ouyang, G., Śmigasiewicz, K., \& Zhou, C. (2014). Testing the stimulus-to-response bridging function of the oddball-P3 by delayed response signals and residue iteration decomposition (RIDE). Neuroimage, 100, 271-280.

Wang, X., Chen, B., Zhu, X., \& Yao, S. (2008a). Event-related potentials of Obsessive-compulsive disorder patients in a Go/Nogo task. Chinese Journal of Psychiatry, 22,276-280.

Wang, Y., Zhou, L., \& Luo, Y. (2008b). The pilot establishment and evaluation of Chinese Affective Words System. Chinese Mental Health Journal, 22, 608-612

West, R., \& Alain, C. (2000). Effects of task context and fluctuations of attention on neural activity supporting performance of the Stroop task. Brain Research, 873(1), 102-111.

West, R., Jakubek, K., Wymbs, N., Perry, M., \& Moore, K. (2005). Neural correlates of conflict processing. Experimental brain research, 167(1), 38-48.

Whitson, L. R., Karayanidis, F., Fulham, R., Provost, A., Michie, P. T., Heathcote, A., \& Hsieh, S. (2014). Reactive control processes contributing to residual switch cost and mixing cost across the adult lifespan. Frontiers in psychology, 5. doi: 10.3389/fpsyg.2014.00383.

Zurrón, M., Pouso, M., Lindín, M., Galdo, S., \& Díaz, F. (2009). Event-related potentials with the Stroop colour-word task: timing of semantic conflict. International Journal of Psychophysiology, 72(3), 246-252.

Zurrón, M., Ramos-Goicoa, M., \& Díaz, F. (2013). Semantic Conflict Processing in the Color-Word Stroop and the Emotional Stroop Event-Related Potential (ERP) Correlates. Journal of Psychophysiology, 27(4), 149-164. 